\title{
Open-face tunnelling effects on non-displacement piles in clay - part 1: centrifuge modelling techniques
}

\author{
M. G. WILLIAMSON*, M. Z. E. B. ELSHAFIE $\uparrow$, R. J. MAIR $\uparrow$ and M. D. DEVRIENDT
}

\begin{abstract}
A research programme conducted at the University of Cambridge geotechnical centrifuge provided high-quality data on the interaction effects of open-faced tunnelling beneath non-displacement piles in clay. This paper presents details of the novel centrifuge package, including the reinforced composite piles used to measure loads during the centrifuge tests. Attention is particularly drawn to the importance of temperature compensation and the corresponding effect on the model piles. Results from maintained pile load tests conducted in the centrifuge are presented; through photogrammetric techniques, these are compared with data from pile load cells. The results, also compared with analytical $t-z$ power-law modelling of the soil stress-strain behaviour based on triaxial tests, illustrate the importance of modelling the full history of both soil and piles prior to any subsequent tunnellinginduced loading. The experimental results of the simulated tunnelling tests on piles are presented and compared with simple analytical solutions in a companion paper.
\end{abstract}

KEYWORDS: piles \& piling; soil/structure interaction; tunnels \& tunnelling

\section{INTRODUCTION}

With over half of humanity now living in urban areas, the demand on space and new transport infrastructure is unprecedented. The limited availability of surface space in major cities makes the demand for underground infrastructure, which often involves major tunnelling projects, increasingly more compelling. As a result, the construction of new underground railways, sewers and roadways is being undertaken in highly populated urban cities such as London, Amsterdam, Shanghai, Singapore and Hong Kong and many others using various tunnelling techniques.

The stress changes from such tunnelling activities result in soil movements that propagate through the soil and are eventually observed as settlement and horizontal displacements at the ground surface. Significant research has gone into the prediction and observation of the effect of these ground movements on buildings supported by shallow foundations (e.g. Burland, 1997; Potts \& Addenbrooke, 1997; Franzius et al., 2006; Farrell, 2010; Mair, 2011). However, there has been significantly less research on the effects of tunnelling-induced ground movements on piled foundations and the resulting interaction with the overlying structure(s) that these foundations support.

Previous experimental modelling work investigating the effects of tunnelling on piles has mainly focused on the effects of tunnelling on driven piles (Loganathan et al., 2000; Jacobsz et al., 2004; Marshall \& Mair, 2011). Driven piles are considered a 'worst-case' scenario, particularly in sands where the stress bulb at the pile toe is subjected to stress

Manuscript received 30 January 2017; revised manuscript accepted 9 August 2017. Published online ahead of print 18 September 2017. Discussion on this paper closes on 1 April 2018, for further details see p. ii.

Published with permission by the ICE under the CC-BY license. (http://creativecommons.org/licenses/by/4.0/)

* Mott MacDonald Limited, Cambridge, UK (Formerly University of Cambridge).

$\dagger$ Department of Engineering, University of Cambridge, Cambridge, UK.

t. Ove Arup and Partners Limited, London, UK relief from tunnelling-induced ground movements that may result in pile failure, as shown by Marshall (2012). However, in order to reduce noise and vibration effects, the majority of piles constructed in major cities in recent years have been non-displacement (bored) piles, rather than driven piles. Field data from well-documented case histories are also rare, but works include those reported by Coutts \& Wang (2000), Takahashi et al. (2004), Jacobsz et al. (2005), Kaalberg et al. (2005), Selemetas (2005), Kaalberg et al. (2014) and Mair \& Williamson (2014). This lack of insight and the shortage of field data have led practitioners to adopt highly conservative approaches when designing tunnel alignments and expensive mitigation measures are often adopted for new tunnel constructions close beneath pile foundations. Jacobsz et al. (2005) showed that the use of expensive mitigation methods applied to a piled bridge foundation was unnecessary and could have been avoided with a better understanding of the tunnel-pile-soil interaction.

The majority of previous research, in particular analytical work, has concentrated on tunnelling adjacent to, as opposed to beneath, piled foundations (e.g. Loganathan et al., 2001; Xu \& Poulos, 2001; Kitiyodom et al., 2005; Huang et al., 2009; Zhang et al., 2011; Basile, 2012; Zhang et al., 2013). This has resulted in concerns over the structural integrity of the foundations due to increased lateral loading and bending moments on the affected piles. However, tunnelling beneath piled foundations, as shown in Fig. 1, has often been ignored owing to a lack of well-documented field data or experimental data from which analytical and numerical models can be developed and verified. Well-documented experimental data from centrifuge model tests of tunnelling beneath driven piles, as reported by a number of researchers including Jacobsz et al. (2004), Marshall \& Mair (2011) and Marshall (2012), showed significant pile settlements due to reduction in the pile base capacity caused by interaction of the tunnelling (causing stress relief) with the existing pile stress bulb.

In contrast, non-displacement piles, which are shaftcontrolled, are not subject to the loss of capacity seen for driven piles in sand. Case studies for tunnelling beneath non-displacement piles in clay have generally been very 


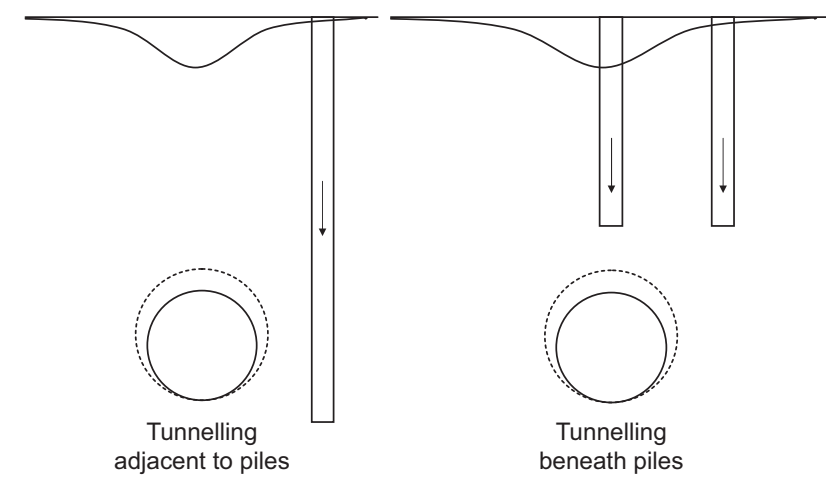

Fig. 1. Tunnelling adjacent to piles and tunnelling beneath piles

limited; the most relevant data are from a field trial conducted in Dagenham for the channel tunnel rail link (now HS1), reported by Selemetas et al. (2005), and those reported by Jacobsz et al. (2005) for a series of piled bridge piers. Both studies showed increased pile head displacement when compared with the adjacent ground surface settlement; however, in both cases, the ratio of pile head displacement to adjacent ground surface settlement was significantly less than that measured experimentally for driven piles in sand (Jacobsz et al., 2004; Marshall \& Mair, 2011). This would indicate that the effect of stress relief is likely to be small for piles in clay subjected to tunnelling and that the effect of soil displacements and the effect of pile stiffening as described by Jacobsz et al. (2005) may be more significant.

In order to provide high-quality data on the interaction effects of open-face tunnelling beneath non-displacement (predominantly friction) piles in clay, a research programme was conducted using the geotechnical centrifuge at the University of Cambridge (Schofield, 1980). The research programme was designed to facilitate a more fundamental understanding of tunnel-soil-pile mechanisms and to provide a body of data for back-analysis for future analytical and numerical models. Centrifuge modelling was chosen as it allows the simulation of progressively increasing volume losses up to large values (10\%). Although clearly undesirable in the field, high volume losses provide valuable information to aid understanding of the mechanisms of pile behaviour when subjected to tunnelling-induced ground movements. Significant advancements in finite-element modelling have been made in recent years, but high-quality experimental data are still invaluable for the calibration and verification of these advanced soil models, as well as for less complicated approaches including boundary value problems.

A description of the novel centrifuge package developed to investigate the behaviour of piles subjected to tunnellinginduced movements is presented in the first part of this paper. The innovative use of a novel model composite pile together with the effective use of particle image velocimetry (PIV) to obtain high-quality data is then discussed. Attention is then drawn to the importance of temperature compensation and the assessment of residual loading on the model piles, which developed during the model preparation process, before load testing in the centrifuge. The second part of the paper presents results from maintained pile load testing carried out in the centrifuge at $75 \mathrm{~g}$; the load-displacement curves obtained from the model piles are presented for three tests (tests PC2, PC4 and PC5). The high-quality PIV data recorded during load testing were used to produce strain profiles along the entire length of the model piles; these profiles were compared with data from strain gauges attached to the piles and very good agreement was found. The third part of the paper presents analytical solutions, developed independently in this research, to investigate the model pile loading behaviour at different stages of the centrifuge tests, including the consolidation stage (as detailed in the section 'Illustration of pile capability - pile load tests'). The analytical solution developed uses non-linear shear stress $(t)$ against displacement $(z)$ load-transfer model curves to describe the interface between the model piles and the surrounding clay soil. The non-linearity of the $t-z$ curves was derived from a power-law stress-strain relationship based on triaxial tests conducted to characterise the clay soil behaviour (Vardanega et al., 2012a). Finally, the centrifuge model tests results are compared and contrasted with the analytical results and some interesting conclusions are presented.

In a companion paper (Williamson et al., 2017), experimental results of the simulated tunnelling tests on piles are presented and compared with simple analytical solutions.

\section{BACKGROUND}

The use of geotechnical centrifuges for investigating tunnelling movements and tunnel behaviour has been extensive, and the use of photographic techniques along a plane of symmetry has traditionally been adopted to measure subsurface soil displacements (Potts, 1976; Schofield, 1980). Historic centrifuge data are limited to displacements associated with the development of higher strains in the soil (of the order of 20\%) close to failure, as described by Mair (1979). Such data have been considerably improved with the advent of package-mounted cameras which, in conjunction with centrifuge slip rings, allow the transmission and capture of live data from the centrifuge package at high $\boldsymbol{g}$-levels, as described by Grant \& Taylor (2000). However, such experiments were stress-controlled with an air-filled rubber cylinder modelling a tunnel cavity and air pressure reduction used to simulate volume loss. Although these methods are capable of modelling tunnel failure, as shown by Taylor (1998), they provide somewhat inconsistent displacement data, particularly when looking carefully at the measured soil displacements away from the plane of symmetry. Bezuijen \& van der Schrier (1994) used a concentrically contracting floating tunnel to simulate tunnelling volume loss; such a model is incompatible with the use of photogrammetric techniques as maintaining plane strain conditions at the plane of symmetry is not feasible. Loganathan et al. (2000) described the use of a fluid-filled cavity with the extraction of known quantities of fluid to simulate volume loss; the tunnel was allowed to float and, as such, was again incompatible with photogrammetric techniques. Marshall \& Mair (2011), Farrell et al. (2014) and Divall (2013) made use of fixed fluid-filled cavities that allowed free movement of the soil during centrifuge acceleration and consolidation but which also allowed plane strain tunnelling movements at the plane of symmetry for photogrammetric techniques. While none of these studies investigated the problem of tunnelling beneath non-displacement piles in clay, the centrifuge modelling techniques adopted are directly relevant to the research work presented in this paper.

Observing the behaviour of model piles with PIV during $1 \boldsymbol{g}$ and centrifuge testing has been attempted by a number of researchers, with limited success. White \& Bolton (2004) performed plane strain tests, at $1 \boldsymbol{g}$, in a pressurised calibration chamber to model the installation effects of jacked displacement piles in sands; measurements of the loading at the toe were made through the use of a button load cell, while PIV was used to measure the pile shaft displacement and adjacent soil movements. Marshall \& Mair (2011) described the use of a semi-circular machined aluminium jacked/driven pile with strain gauging to allow the measurement of pile loading along the pile shaft with limited success; 
pile bending was the primary factor attributed to the erroneous shaft readings. Similarly, Liu (2010) described a number of different shaft designs for semi-circular model cone penetration test penetrometers; most were unsuccessful and again this was attributed to bending of the model penetrometers under loading. Liu (2010) did show that applying strain gauges along the model penetrometer centroid improved the data quality significantly; however, as only quarter-bridge strain gauges were used, they did not allow full bending or temperature compensation. Following on from this work, Williamson et al. (2013) described the use of semi-circular aluminium machined 'non-displacement' piles with load cells placed along the pile centroid at the pile head and toe with full Wheatstone bridges to provide bending and temperature compensation. Williamson et al. (2013) also loaded the piles directly through the pile centroid to minimise any applied bending to the pile head; the results showed significant improvement and were consistent at high stresses. However, even though such a method was capable of measuring the pile head and base loads, it was not sufficient for the measurement of shaft loads as required for investigating the behaviour of non-displacement piles in clay.

Centrifuge modelling of tunnelling on piles has been modelled by a number of authors, with the majority conducted without the use of a plane of symmetry (Bezuijen \& van der Schrier, 1994; Loganathan et al., 2000; Jacobsz et al., 2004; Ong, 2009). A more recent study carried out by Marshall \& Mair (2011), using semi-circular model piles, incorporated the use of a plane of symmetry for driven piles in sand, which provided extensive data for the pile failure mechanism when subjected to tunnelling. Both Jacobsz et al. (2004) and Marshall \& Mair (2011) carried out experiments with piles located directly above and away from the tunnel centre-line. In both studies, a variation was reported in the loading behaviour between the tunnel centre-line piles and those piles off the centre-line, prior to tunnelling being simulated; this indicates that tunnel-lining flexibility may have had an influence on the pile behaviour, particularly at or near the pile base. For piles that are largely shaft-controlled, such behaviour is less likely, with much less load shed from the pile base and the majority of the load being shed through shearing of the soil at distance from the tunnel.

More recent centrifuge work was conducted using shaftcontrolled piles in sand (Lee \& Chiang, 2007; $\mathrm{Ng}$ et al., 2013). These piles, unlike those used by Marshall \& Mair (2011) and Jacobsz et al. (2004), accounted for the majority of their load from shaft friction, not end-bearing. Lee \& Chiang (2007) showed that the effect of the factor of safety on the pile capacity was significant in the amount of pile displacement seen upon tunnelling-induced settlements. However, these piles were installed such that a large amount of the load resistance was derived from shaft friction. As reported by a number of authors, including Lehane $e t$ al. (2005) and Garnier et al. (2007), particle size errors associated with the mobilisation of shaft friction for piles in sand are significant. Such errors make interpretation of the mechanisms very difficult; in contrast, particle size errors are generally negligible for piles in clay with normalised roughness values greater than $0 \cdot 1$ (Garnier \& Konig, 1998). All the tests reported in this paper were conducted in clay, as described in detail in later sections. The normalised roughness value for all the model piles used in this research was, on average, greater than $2 \cdot 0$.

\section{CENTRIFUGE PACKAGE}

The centrifuge package used in this testing series was a highly modified version of the 'Take Box' described by

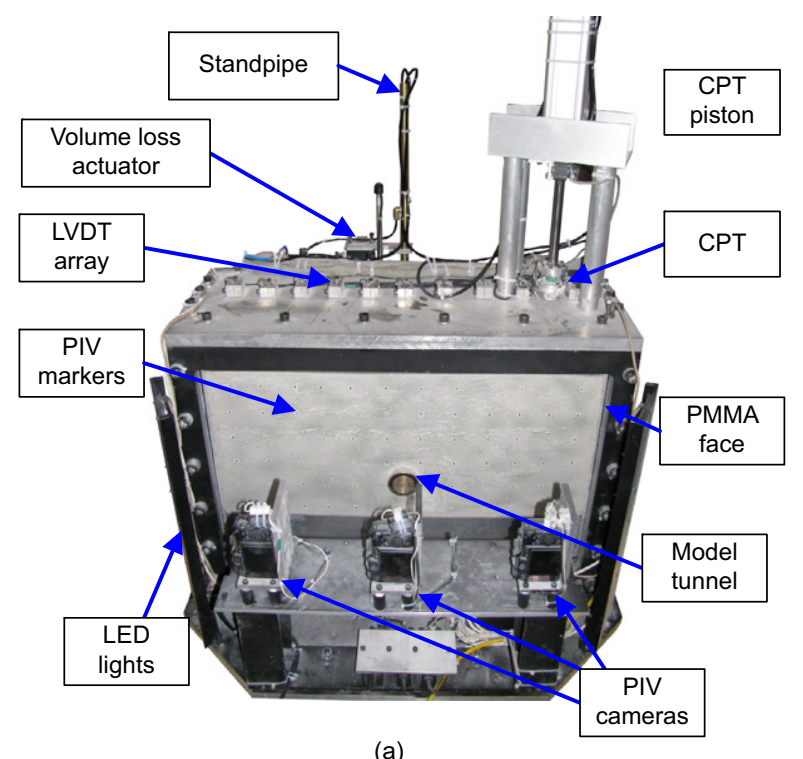

(a)

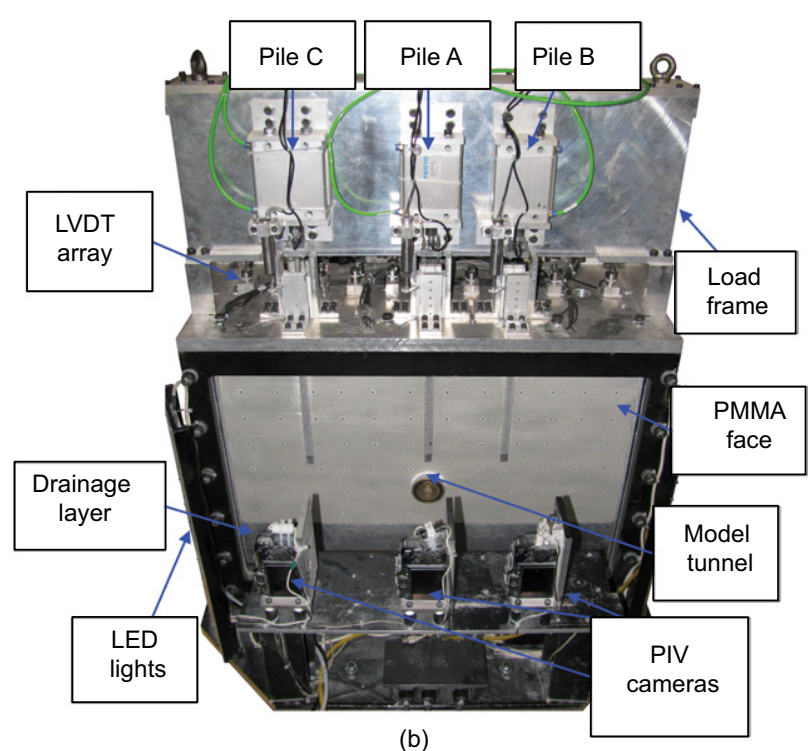

Fig. 2. (a) Greenfield centrifuge package. (b) Pile-tunnel centrifuge package. CPT, cone penetrometer test; LED, light-emitting diode; LVDT, linear voltage differential transducer; PMMA, poly(methyl methacrylate)

McMahon (2012). It is shown in Figs 2(a) and 2(b) for greenfield and pile-tunnel tests, respectively. A detailed description of the package and the setup is given elsewhere (Williamson, 2014), but the following provides a summary of the critical aspects.

The package had inner usable dimensions of $790 \times 200 \times 535 \mathrm{~mm}$ (width $\times$ depth $\times$ height). The model tunnel was an improved version of the model used by Marshall \& Mair (2011) and its placement within the centrifuge package is shown in Fig. 3. A base drainage layer of machined aluminium was used to prevent softening of the model following removal from the consolidometer (see Williamson (2014) for further details). Double drainage of the model was permitted, with water applied to the model within the centrifuge from both the base and the clay surface. A series of ten linear variable differential transducers (LVDTs) was used to measure the soil settlement with thin poly(methyl methacrylate) (PMMA) footings threaded onto the LVDT spindle tips. 


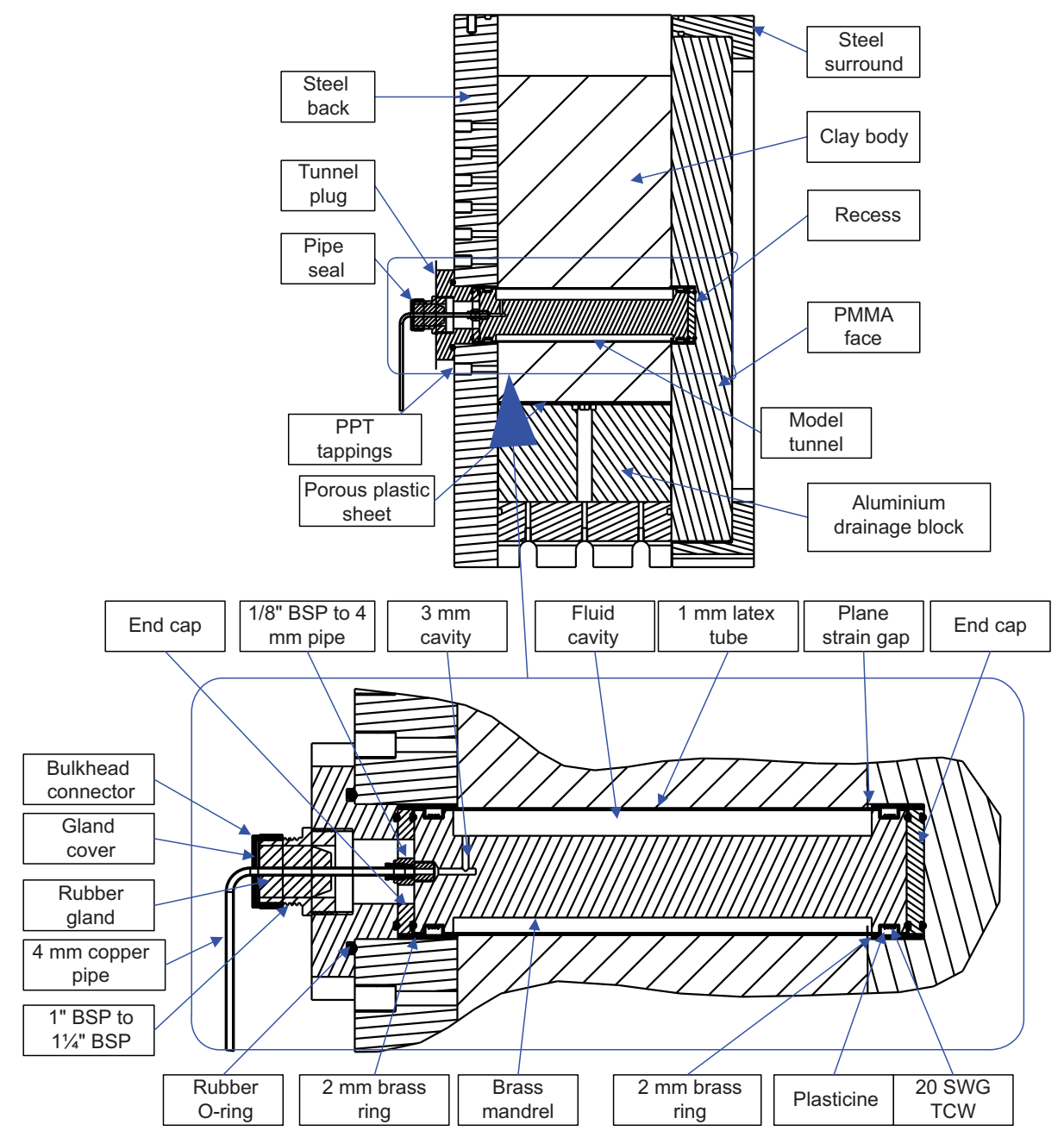

Fig. 3. Tunnel placement with fitting and details $(B S P=$ British standard pipe; $1 "=25.4 \mathrm{~mm})$. PPT, pore pressure transducer; SWG TCW, standard wire gauge tin copper wire

\section{MODEL PILE}

The model pile is shown in Fig. 4. It was manufactured as a composite of moulded resin with aluminium reinforcement, which allowed strain gauging on a prepared and flat surface. Aluminium was chosen for its relatively high coefficient of thermal expansion $(23 \mathrm{ppm} / \mathrm{K})$ and low stiffness $(E=70 \mathrm{GPa})$. High-resistance strain gauges $(350 \Omega$ ) were chosen to limit thermal effects; this requirement created a constraint on the model pile cross-section. Aluminium 3003-H14 alloy square tubing of section width $\times$ height $\times$ thickness $4.7625 \mathrm{~mm} \times 4.7625 \mathrm{~mm} \times 0.335 \mathrm{~mm}$ and length $304.8 \mathrm{~mm}$ was sourced, providing an axial rigidity of $1.17 \mathrm{MN}$. Several resins were considered. Eventually, in order to address the combined constraints imposed by the model pile stiffness, strength, density, thermal coefficient and porosity in addition to the practical issues of casting thickness and curing temperature, a casting resin consisting of Araldite CW 1304 filler and Aradur HY 1300 hardener was chosen.

Shear studs were added to ensure composite action between the resin and the aluminium section. The curved faces were uniformly roughened prior to calibration.

Full Wheatstone bridges with temperature and bending compensation were used at six positions along the model pile shaft, as shown in Fig. 4, to measure the axial load in the model piles.

The model pile loading system was designed to simulate a non-displacement pile condition, with the pile density closely matching the soil and head loading negligible until centrifuge consolidation was complete (confirmed by the load cells). Pile loading was then applied to ensure a low-strain condition at the pile-soil interface. The pile loading system used in this study, consisting of a piston, load cell, cable suspension, pile caps and pile guides, is shown in Fig. 5.

As described by Williamson (2014), a test pile was added to the centrifuge setup to provide an estimate of the pile factor of safety and the pile shaft friction/base load. For this test pile (referred to as pile $\mathrm{C}$ ), a loading pin (with a pinned contact point) was added to allow loading of the pile greater than that provided by the pile cap in a controlled manner (Fig. 5(b)); for the other piles (piles A and B) no pin was used (Fig. 5(a)).

\section{PARTICLE IMAGE VELOCIMETRY}

Recent improvements in the cost and quality of digital compact cameras have led to improvements in PIV without the need for significant alteration of the centrifuge models. The clay was textured using a small quantity of dyed sand to provide contrast for the PIV images. PIV control markers were added to the PMMA for spatial calibration of the image vectors while great care was taken to provide consistent spacing of the markers and to ensure no data in the region of the piles were lost due to marker placement. As noted by White et al. (2003), the image space PIV resolution is a function of image quality; a value of $0 \cdot 1$ pixels is often 

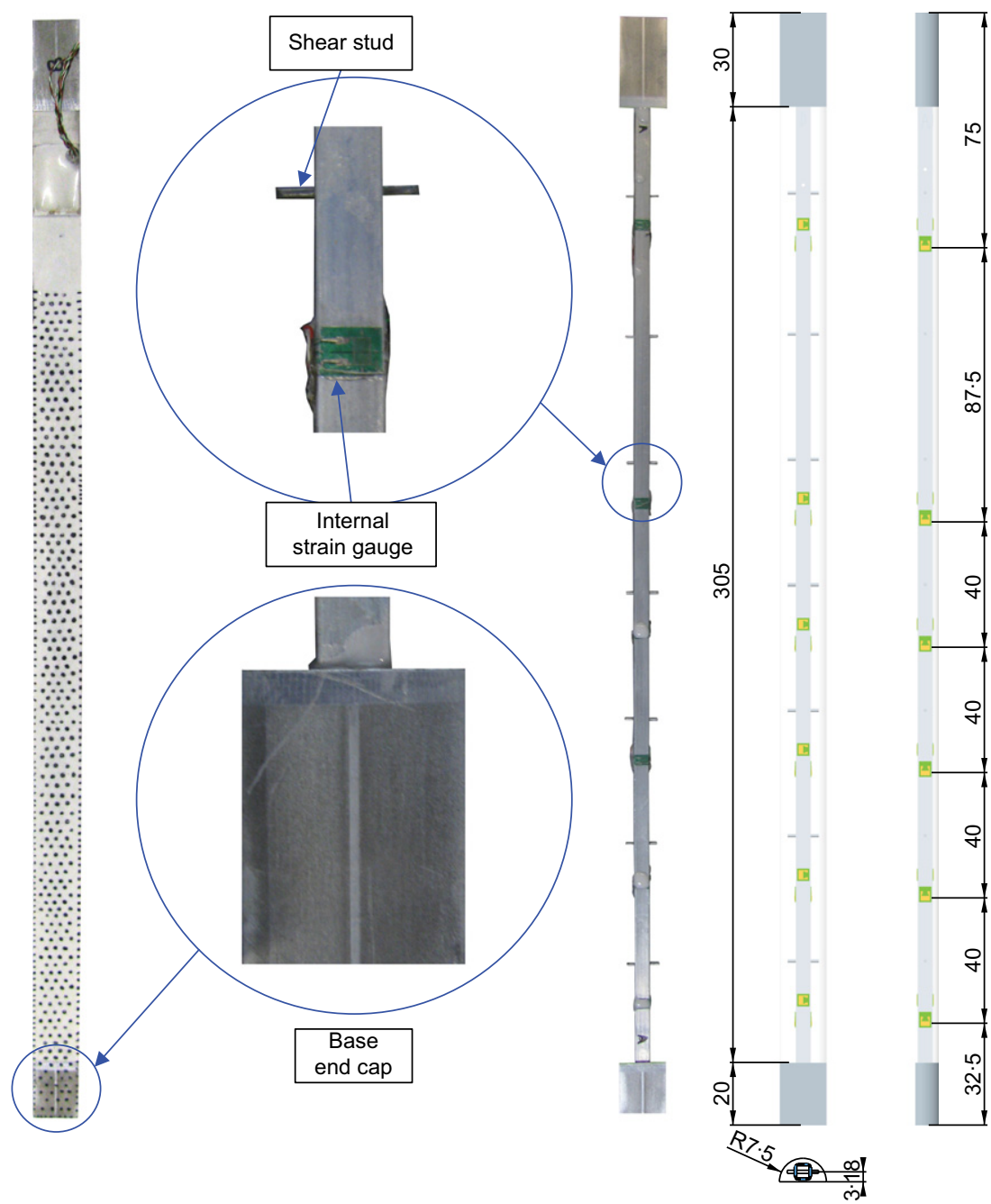

Fig. 4. Pile design (dimensions in $\mathbf{m m}$ )

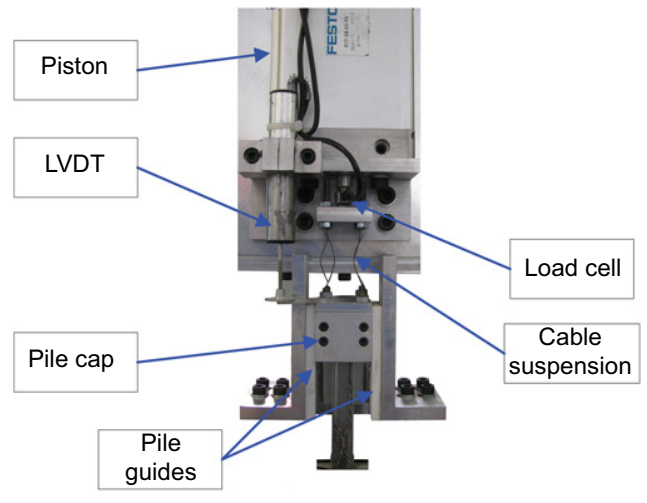

(a)

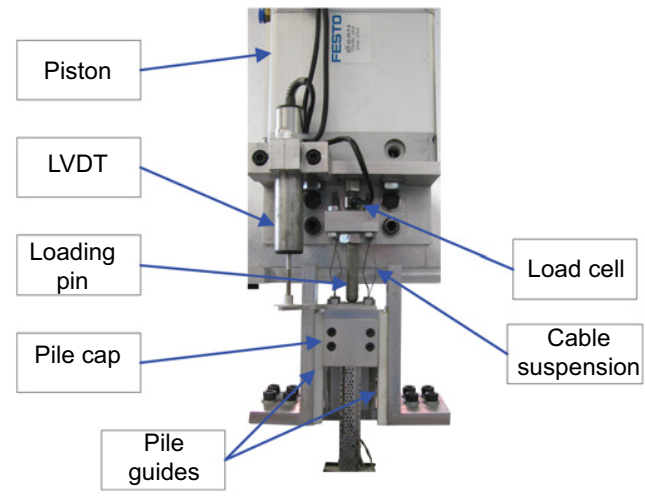

(b)

Fig. 5. Pile loading system

quoted, which in the setup used in this research would lead to an error of approximately $0.01 \mathrm{~mm}$. Photogrammetric errors were measured on consecutive images without movements across the soil body; this showed that $90 \%$ of the spatial errors were below $0.01 \mathrm{~mm}$ while $60 \%$ of these errors were below $0.005 \mathrm{~mm}$.

The model piles were textured with a series of dots to ensure high-quality PIV tracking of the pile displacements. The image quality and the representative stiffness of the piles allowed direct PIV measurement of the pile strains for comparison with the measured strain gauge readings when combined with the composite pile modulus (14.4 GPa). Fig. 6 compares the PIV data from pile load tests (conducted on pile $\mathrm{C}$ from the different centrifuge tests) at different soil strength/stiffness values (achieved by applying different pre-consolidation pressures, as detailed by Williamson (2014)); the agreement at working loads (i.e. $P / P_{\max }<0 \cdot 5$ ) is reasonable, with better agreement at higher loads. These graphs illustrate both the quality of the PIV data and the ability of the piles to accurately measure the applied loads. 

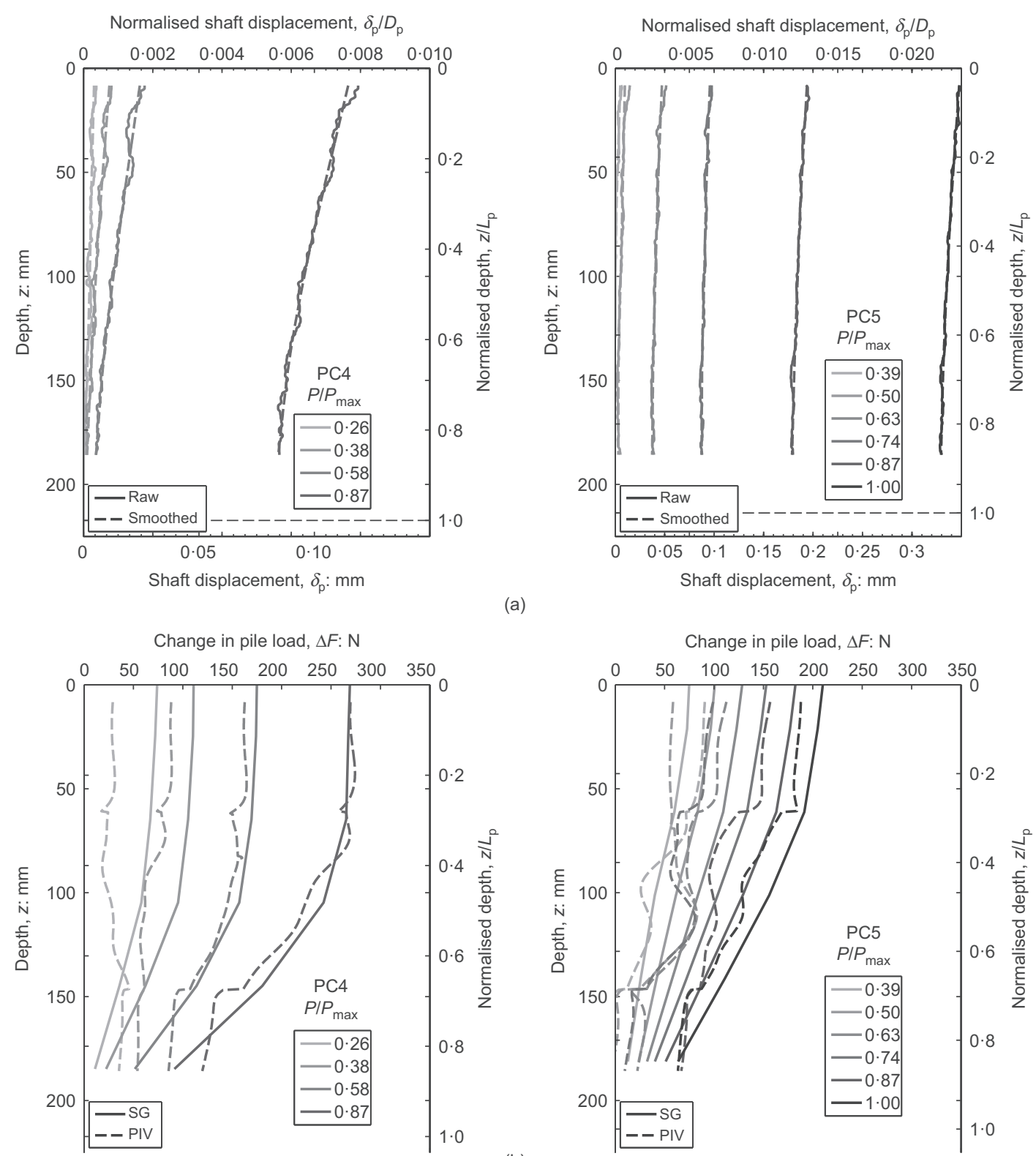

(b)

Fig. 6. PIV pile data at varying loads: (a) settlement along shaft from PIV; (b) comparison of load change calculated from strains measured in pile directly from PIV with strain gauge (SG) data

\section{MODEL PREPARATION}

Preparation of each centrifuge model took approximately 7 weeks due to the time required for clay consolidation and swelling prior to clay cutting and placement within the centrifuge. Clay (mixed under a vacuum) was poured as slurry at a water content of $1 \cdot 2$.

The maximum load for each clay specimen was carefully chosen to achieve the required clay strength and to ensure that this was consistent between tests. The mediumto high-strength tests (average $c_{\mathrm{u}}=80 \mathrm{kPa}$ ) were preconsolidated to a pressure of $800 \mathrm{kPa}$ to simulate a stiff clay while the medium-strength test (average $c_{\mathrm{u}}=50 \mathrm{kPa}$ ) was pre-consolidated to a pressure of $400 \mathrm{kPa}$ to provide a softer clay.

Careful cutting of the clay was performed when placing the model tunnel in the package with the use of a thin-walled cutter as shown in Fig. 7 (for further details see Williamson (2014)). A thin wall cutter was used to cut the pile cavities prior to placing the piles in the cavities; good contact between the piles and the clay was maintained.

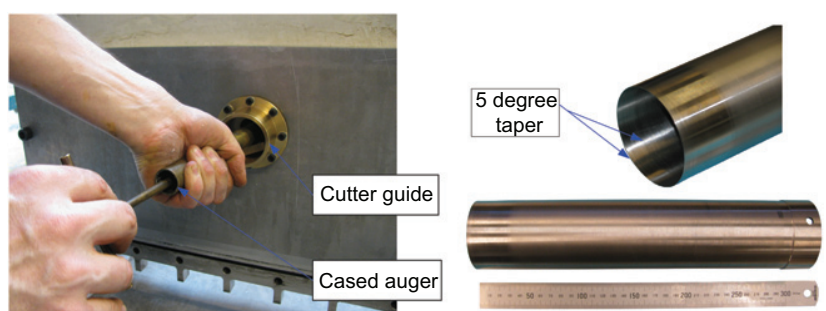

Fig. 7. Model preparation: tunnel cutting

Monitoring of the pore water pressures within the clay body showed that no clay softening or pore pressure reductions were measured during model preparation. However, when the clay was transported to the centrifuge, overnight pore pressure reductions were visible and the effect of this on the pile loading conditions is discussed in the following section. Table 1 provides a summary of the tests reported in this paper while Fig. 8 shows schematic diagrams 
Table 1. Summary of tests

\begin{tabular}{|c|c|c|c|c|c|c|}
\hline Test & $\begin{array}{l}\text { Consolidation } \\
\text { pressure: } \mathrm{kPa}\end{array}$ & Piles & Pile test on pile C? & Tunnel or pile test first & Pile variable & In this paper \\
\hline $\begin{array}{l}\text { GC1 } \\
\text { PC2 } \\
\text { PC4 } \\
\text { PC5 } \\
\text { PC6 }\end{array}$ & $\begin{array}{l}8 \overline{800} \\
800 \\
400 \\
800\end{array}$ & $\begin{array}{l}\text { No (greenfield) } \\
\text { Yes } \\
\text { Yes } \\
\text { Yes } \\
\text { Yes }\end{array}$ & $\begin{array}{l}\overline{\bar{Y}} \\
\text { Yes } \\
\text { Yes } \\
\text { No }\end{array}$ & $\begin{array}{l}\text { Tunnel } \\
\text { Pile test } \\
\text { Tunnel }\end{array}$ & $\begin{array}{l}\text { Reference test } \\
\text { Low factor of safety* } \\
\text { Low } c_{\mathrm{u}} / E^{*} \\
\text { Pile position* }\end{array}$ & $\begin{array}{l}\text { No } \\
\text { Yes } \\
\text { Yes } \\
\text { Yes } \\
\text { No }\end{array}$ \\
\hline
\end{tabular}

* Parameter relative to the corresponding parameter in the reference test.

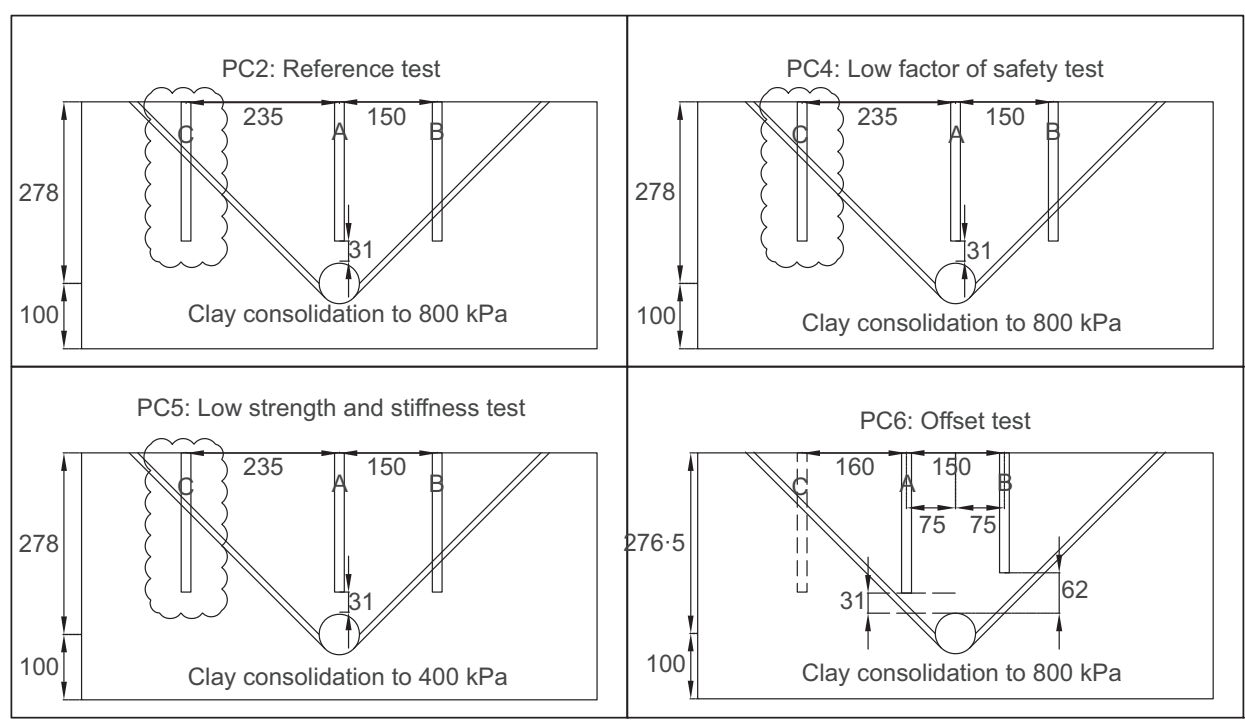

Fig. 8. Pile test layouts with $45^{\circ}$ zones of influence for information (dimensions in mm)

of the tests. Pile $\mathrm{C}$, used for the pile load tests, is highlighted in the diagrams. The pile variable relates to the tunnelling aspects described in the companion paper (Williamson et al., 2017) and is relative to test PC2 (the reference test). The locations of piles A and B were chosen to reflect the various zones of influence from previous studies (Jacobsz et al., 2004; Selemetas, 2005).

\section{INITIAL PILE LOADING AND TEMPERATURE COMPENSATION}

Initial pile loading at the start of a centrifuge test is often ignored. This may be appropriate for tests performed in sands where the majority of load is derived from soil self-weight and any initial load is negligible. However, in clay tests, such an approach may not be appropriate given the significant effective stresses derived from negative pore pressures prior to centrifuge loading. In addition, any changes in temperature may have significant effects on both the clay body as well as the piles themselves.

Although several centrifuges worldwide are air conditioned, most models are prepared in areas where temperature is not controlled before they are transferred to the centrifuge. As a result, temperature changes may have a significant impact on the results if not correctly assessed. Similarly, when placed in the centrifuge, even though the clay body may be maintained at a constant temperature, the addition of water to the model to allow consolidation is generally less controlled and applies (initially) a temperature gradient to the clay body. Such an effect diminishes during the consolidation phase as the water temperature equilibrates with the ambient temperature in the centrifuge. These temperature effects are exacerbated seasonally and, as such, may influence the consistency of a suite of tests if measures are not taken to nullify them.

Due to the ventilation setup in the geotechnical centrifuge at the University of Cambridge, maintaining a constant temperature is extremely difficult. Any incurred temperature change should thus be appropriately considered to ensure that the effects are quantified. To assess these effects, pile loads, soil settlement and pore water pressures were monitored to quantify the apparent temperature-induced loads measured by the model piles.

Although the model piles were designed with temperature compensation within each Wheatstone bridge strain gauge arrangement, it was expected they may experience some apparent change in load due to ambient temperature change prior to installation through to loading in the centrifuge. A systematic approach to eliminating these apparent temperature loads was applied. Each Wheatstone bridge within the model piles was carefully calibrated for varying temperatures in a water bath to provide a calibration factor for voltage changes due to only a change in temperature $\left(c_{T}\right)$ as given by equation (1).

$$
c_{T}=\left.\frac{\partial V}{\partial T}\right|_{P=0}
$$

For all of the centrifuge tests, the ambient external temperatures and the temperature within the centrifuge pit were measured throughout the tests. These were also measured upon placement of the package in the centrifuge on the day prior to the tests. To verify this methodology, a thermistor was placed on the surface of the model in one of the tests (test PC6) and was monitored prior to and throughout the installation of the package within the 
centrifuge. This was subsequently compared with the measured ambient and centrifuge pit temperature and was found to agree well with the ambient temperature prior to the centrifuge being operated. During operation of the centrifuge, the heat generated was found to increase the pit temperature by $6^{\circ} \mathrm{C}$ from the measured temperature outside of the pit for the majority of tests; however, lower temperature was recorded within the centrifuge pit for test (PC6) owing to the installation of a replacement motor that generated less heat during the test.

During test PC6, pile loads were monitored from placement in the clay until the end of the centrifuge test over a period of approximately $72 \mathrm{~h}$. No significant change in loading was observed prior to placement within the centrifuge pit owing to a relatively consistent ambient temperature in the laboratory and careful control of the soil body to prevent loading of the piles through straining caused by evaporation or swelling. Following placement within the centrifuge pit, a change in load due to temperature change was evident.

Figures 9(a)-9(d) show the raw pile load data for tests PC2, PC4, PC5 and PC6 respectively, with and without applying temperature compensation to take account of changes from ambient temperature; the force sign convention used here and in the companion paper (Williamson et al., 2017) is negative for tension and positive for compression. For test PC2 (Fig. 9(a)), due to a problem with the data acquisition, no data were captured upon placement of the centrifuge package. However, as the setup, ambient and overnight temperatures were very similar to those in test PC4 (Fig. 9(b)), the data from test PC4 were used to conduct the temperature compensation for test PC2.

The time required for consolidation of the clay in the centrifuge was $8-10 \mathrm{~h}$ and, over this time, the temperature of the centrifuge pit was shown to stabilise. In all the tests, as shown in Figs 9(a)-9(d), the effect of temperature variation should be taken into account; otherwise, invalid conclusions may be drawn from the load distribution before, and therefore after, pile head loading is applied.

\section{ILLUSTRATION OF PILE CAPABILITY - PILE LOAD TESTS}

The experimental results from piles $\mathrm{A}$ and $\mathrm{B}$, which were designed to investigate the effects of tunnelling on piles, are described by Williamson et al. (2017). The results from the pile load tests on pile $\mathrm{C}$ are described in this section.

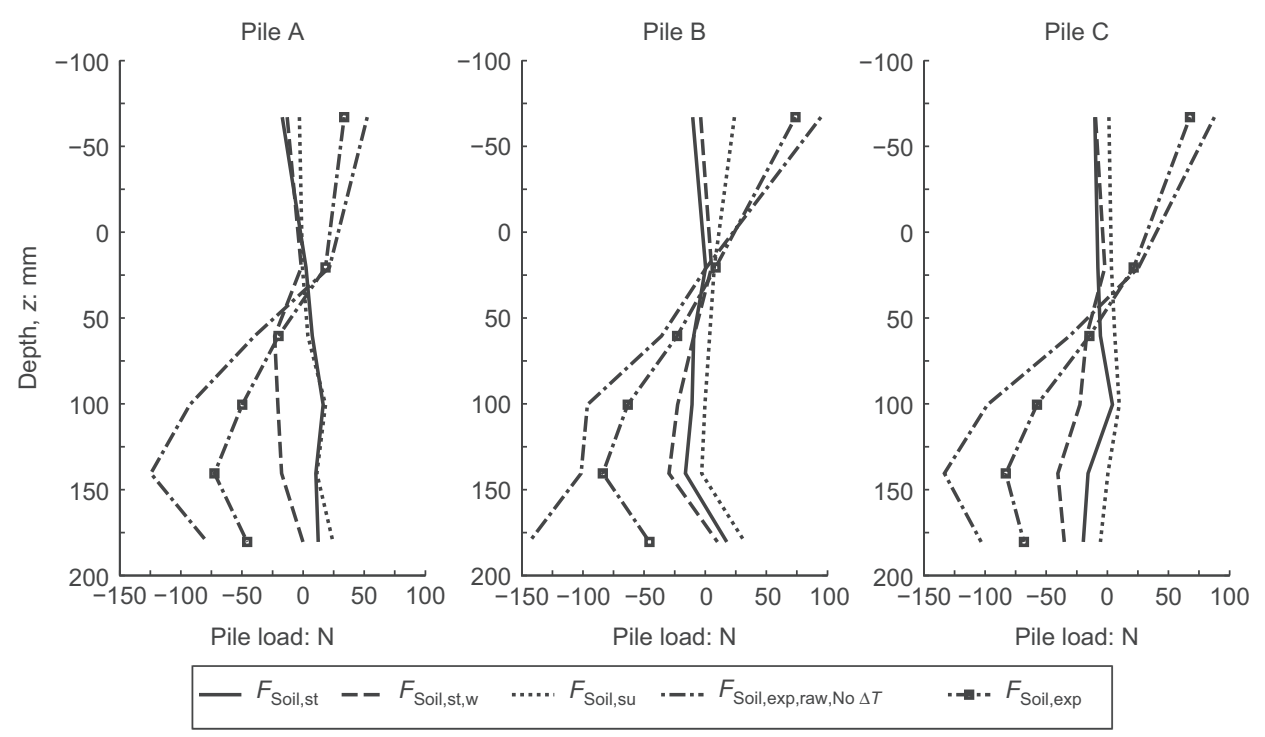

(a)

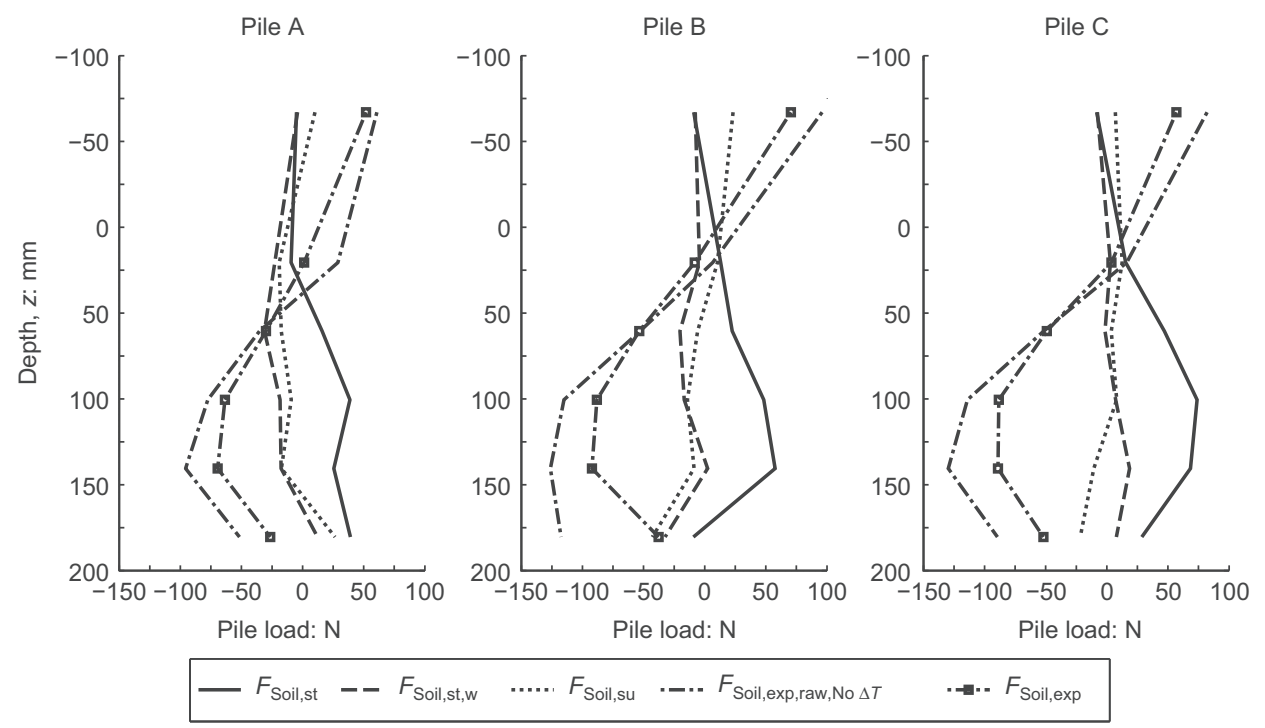

(b)

Fig. 9. Comparison of measured loads with temperature-compensated loads: (a) PC2; (b) PC4; (c) PC5; (d) PC6 (continued on next page) 


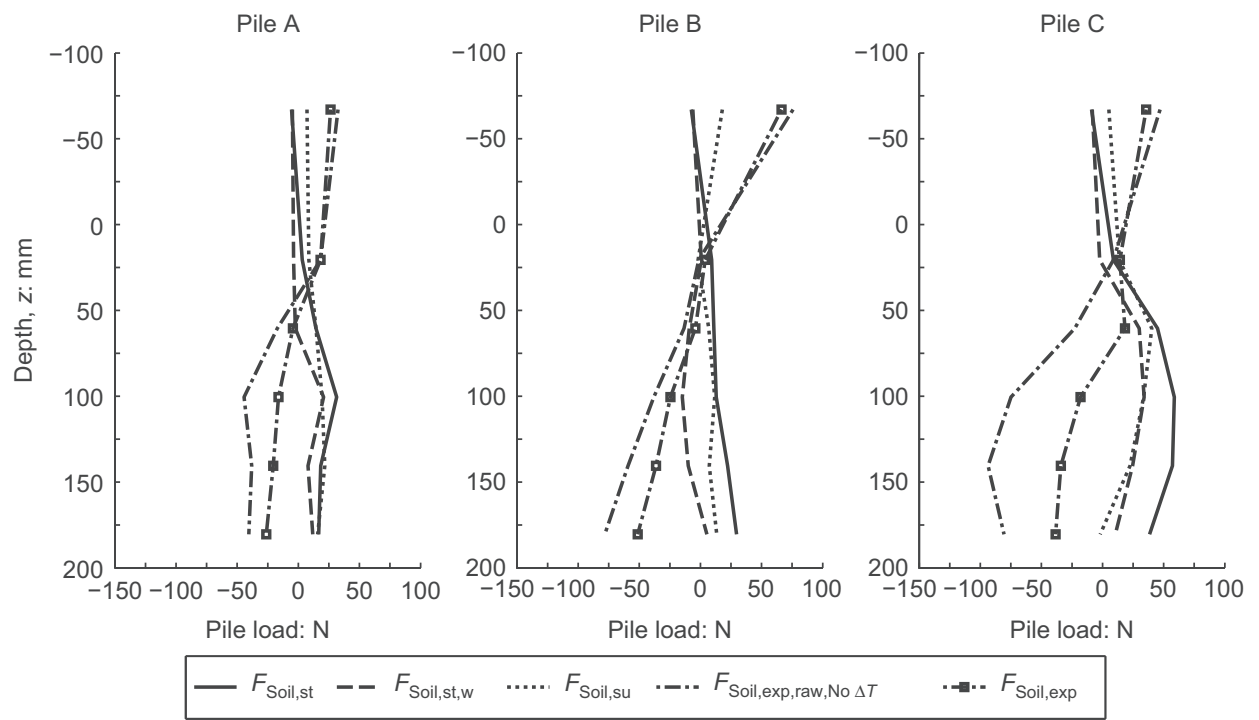

(c)

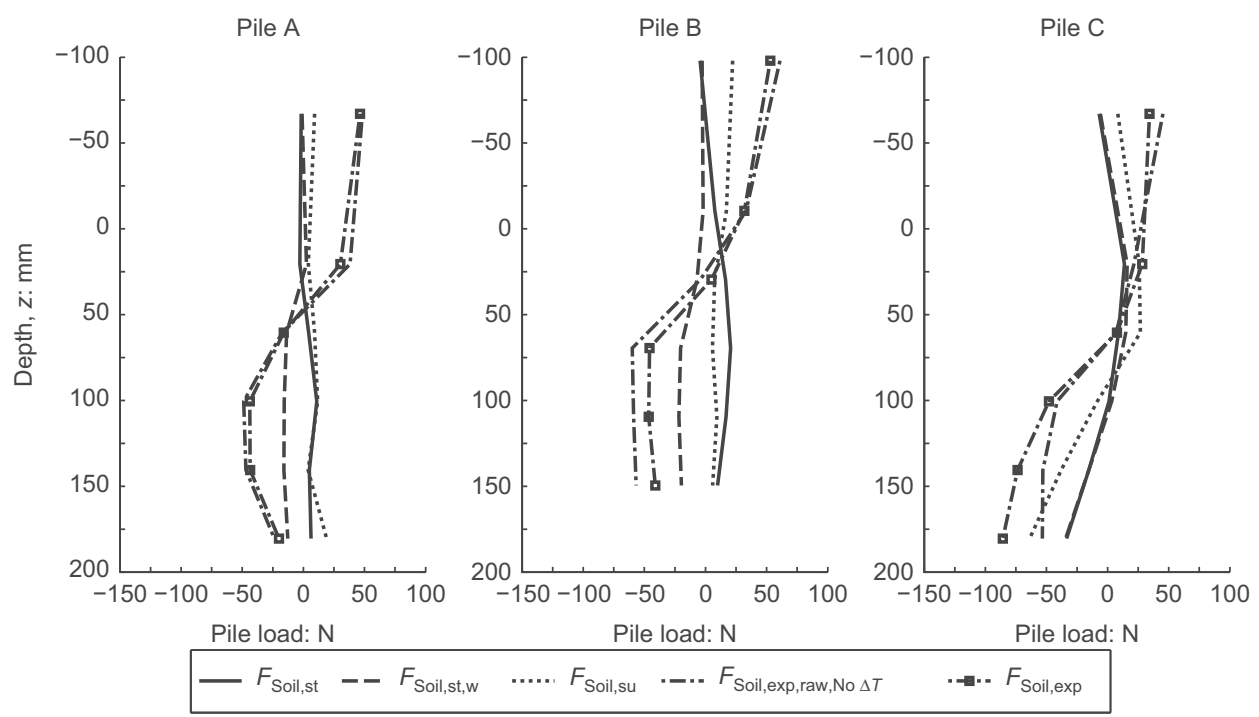

(d)

Fig. 9. Continued

Table 2. Timing of the pile load tests

\begin{tabular}{c|l|c}
\hline Test & Stage & $\begin{array}{c}\text { Pre-consolidation } \\
\text { pressure: kPa }\end{array}$ \\
\hline PC2 & $\begin{array}{l}\text { Prior to tunnelling volume loss } \\
\text { movements } \\
\text { Following tunnelling volume loss } \\
\text { movements }\end{array}$ & 800 \\
PC5 & $\begin{array}{l}\text { Prior to tunnelling volume loss } \\
\text { movements }\end{array}$ & 800 \\
\hline
\end{tabular}

The pile load tests were carried out at different stages, as shown in Table 2. As tests PC2 and PC4 were carried out with the same clay strength (average $c_{\mathrm{u}}=80 \mathrm{kPa}$ ) and pile positioning, these tests were carried out before and after the application of tunnelling-induced ground movements to investigate whether there was any reduction in pile capacity and/or stiffness due to the effects of tunnelling. Unfortunately, due to camera failure, it was not possible to monitor pile/soil displacements for test PC2; however, they were measured for tests PC4 and PC5.

The pile tests were carried out to simulate a maintained load test. However, the rate of loading at the end of the test was found to be greater than that which might be considered appropriate for a maintained load test as specified by the

Table 3. Pile load test loads

\begin{tabular}{l|c|c|c|c|c|c|c|c}
\hline Test & $P_{\text {non-CRP }}: \mathrm{N}$ & $P_{\text {peak }}: \mathrm{N}$ & $P_{\mathrm{CRP}}: \mathrm{N}$ & $\begin{array}{c}\left(\mathrm{d} \delta_{\mathrm{p}, \text { head }} / \mathrm{d} t\right)_{\mathrm{CRP}}: \\
\mathrm{mm} / \mathrm{s}\end{array}$ & $\log 10\left(\frac{\left(\mathrm{d} \delta_{\mathrm{p}, \text { head }} / \mathrm{d} t\right)_{\mathrm{CRP}}}{\left(\mathrm{d} \delta_{\mathrm{p}, \text { head }} / \mathrm{d} t\right)_{\text {SPERW }}}\right)$ & $P_{\text {SPERW: }} \mathrm{N}$ & $P_{\text {max }} * \mathrm{~N}$ & $\alpha$ \\
\hline PC2 & $338 \cdot 0$ & $371 \cdot 4$ & $367 \cdot 9$ & $0 \cdot 226$ & $1 \cdot 66$ & $315 \cdot 6$ & $338 \cdot 0$ & $0 \cdot 67$ \\
PC4 & $288 \cdot 0$ & $358 \cdot 7$ & $356 \cdot 1$ & $0 \cdot 035$ & $0 \cdot 85$ & $328 \cdot 4$ & $328 \cdot 4$ & $0 \cdot 64$ \\
PC5 & $238 \cdot 0$ & $255 \cdot 5$ & $237 \cdot 9$ & $0 \cdot 005$ & $0 \cdot 00$ & $237 \cdot 9$ & $237 \cdot 9$ & $0 \cdot 87$ \\
\hline
\end{tabular}

* $P_{\max }$ is the maximum value of $P_{\text {non-CRP }}$ and $P_{\text {SPERW }}$ 


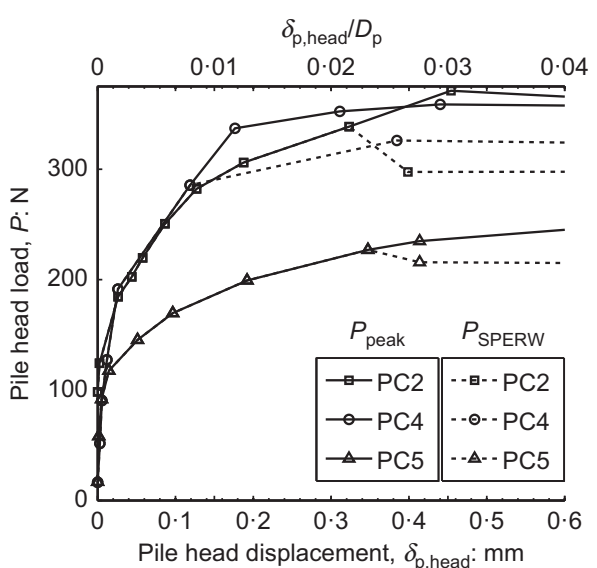

(a)

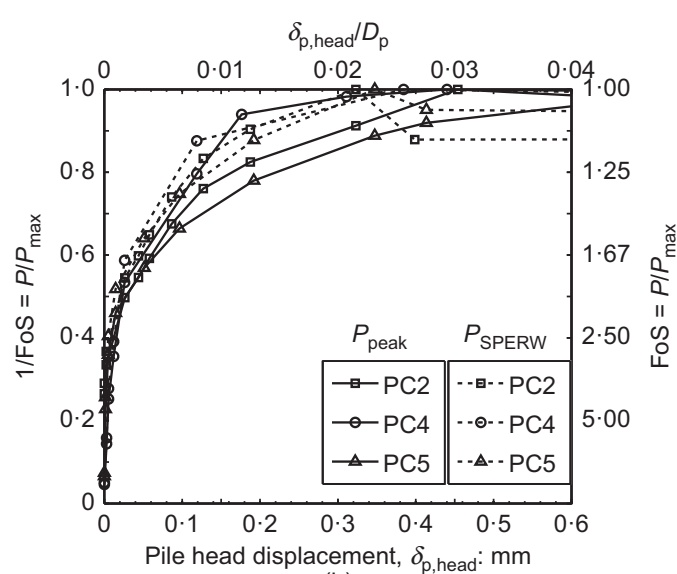

(b)

Fig. 10. (a) Pile head load plotted against pile head displacement; (b) pile head load normalised by the maximum pile head load plotted against pile head displacement $(\mathrm{FoS}=$ factor of safety)
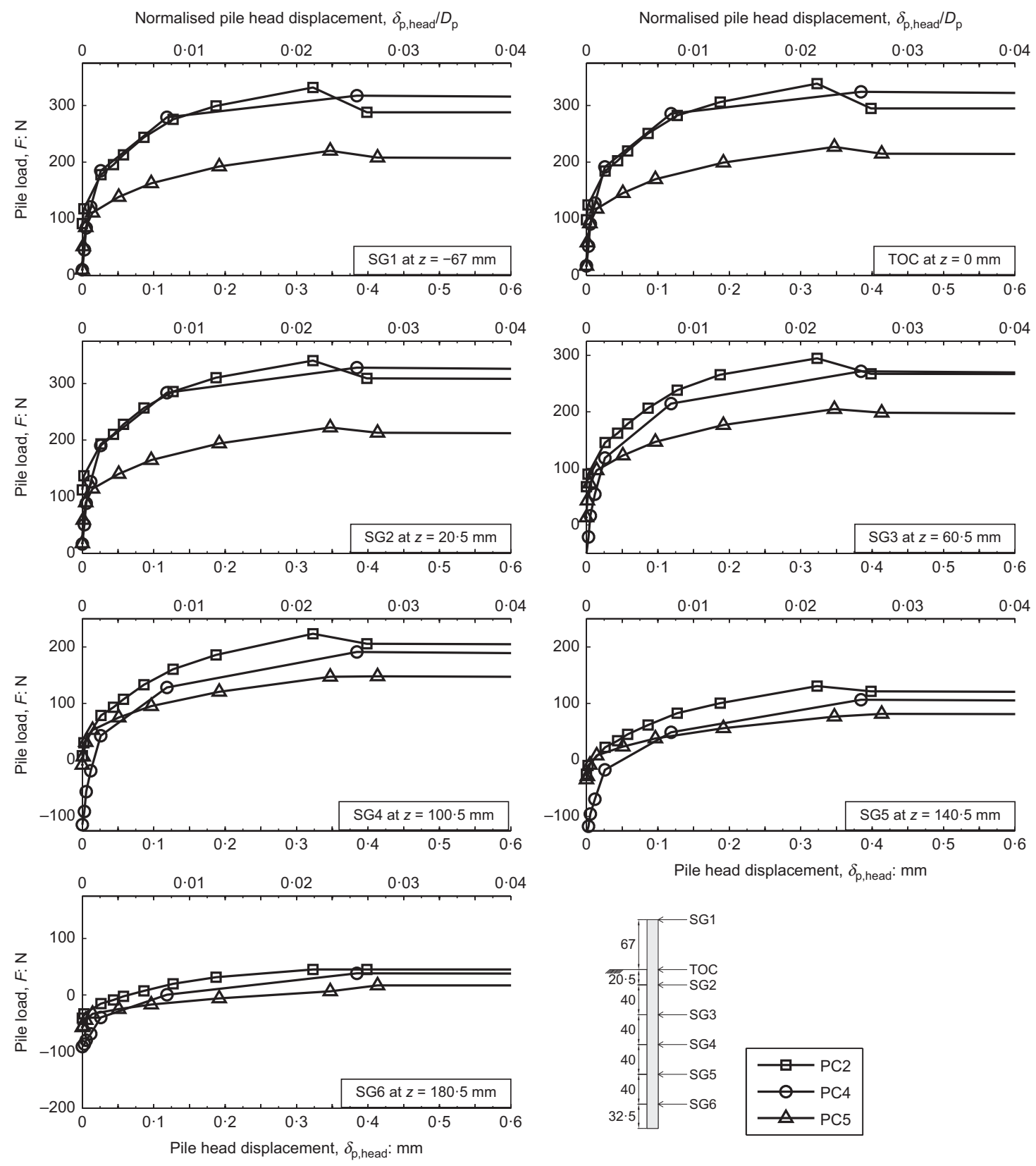

Fig. 11. Strain gauge load plotted against pile head displacement and normalised pile head displacement. TOC, top of clay 
industry standard, the ICE specification for piling and embedded retaining walls (SPERW) (FPS, 2007), and there was some rate variation between tests. To account for this, the maximum load measured, which occurred at a constant rate of penetration (CRP), was reduced in accordance with the work of Kulhawy \& Mayne (1990). The maximum loads prior to the CRP phase, peak, CRP and regressed (SPERW) loads are given in Table 3 . The maximum load in Table 3 is taken as the higher value of the maximum prior to the CRP phase and the regressed (SPERW) value.

As seen from the table, the variation of ultimate capacity between tests PC2 and PC4 was small once the peak load was corrected for rate effects, which would indicate that little strain softening occurred to the shaft upon soil loading.

Figure 10(a) shows plots of pile head load against pile head displacement from both PIV (for PC4 and PC5) and LVDT (for PC2 due to the camera issue) data; the figures show very little variation in the load-settlement characteristics for both PC2 and PC4. Similarly, Fig. 10(b) shows the normalised head load against the same pile head displacement. The differences between the peak and regressed (SPERW) values are illustrated in Fig. 10(a), with differing maximum values as given in Table 3 .

Figure 11 shows the pile head displacement and normalised pile head displacement plotted against the load measurements from each of the strain gauges. When comparing tests PC2 and PC4, the effect of stress reversal for SG4, SG5 and SG6 is evident. The initial loading was highly negative at these locations and, for PC4, the increase in load at these depths was much greater at lower pile head displacements as the upper pile was already close to fully mobilised shaft friction. This is illustrated in Fig. 6, which shows the change in pile load when compared with the relative shaft displacement taken from the PIV data.
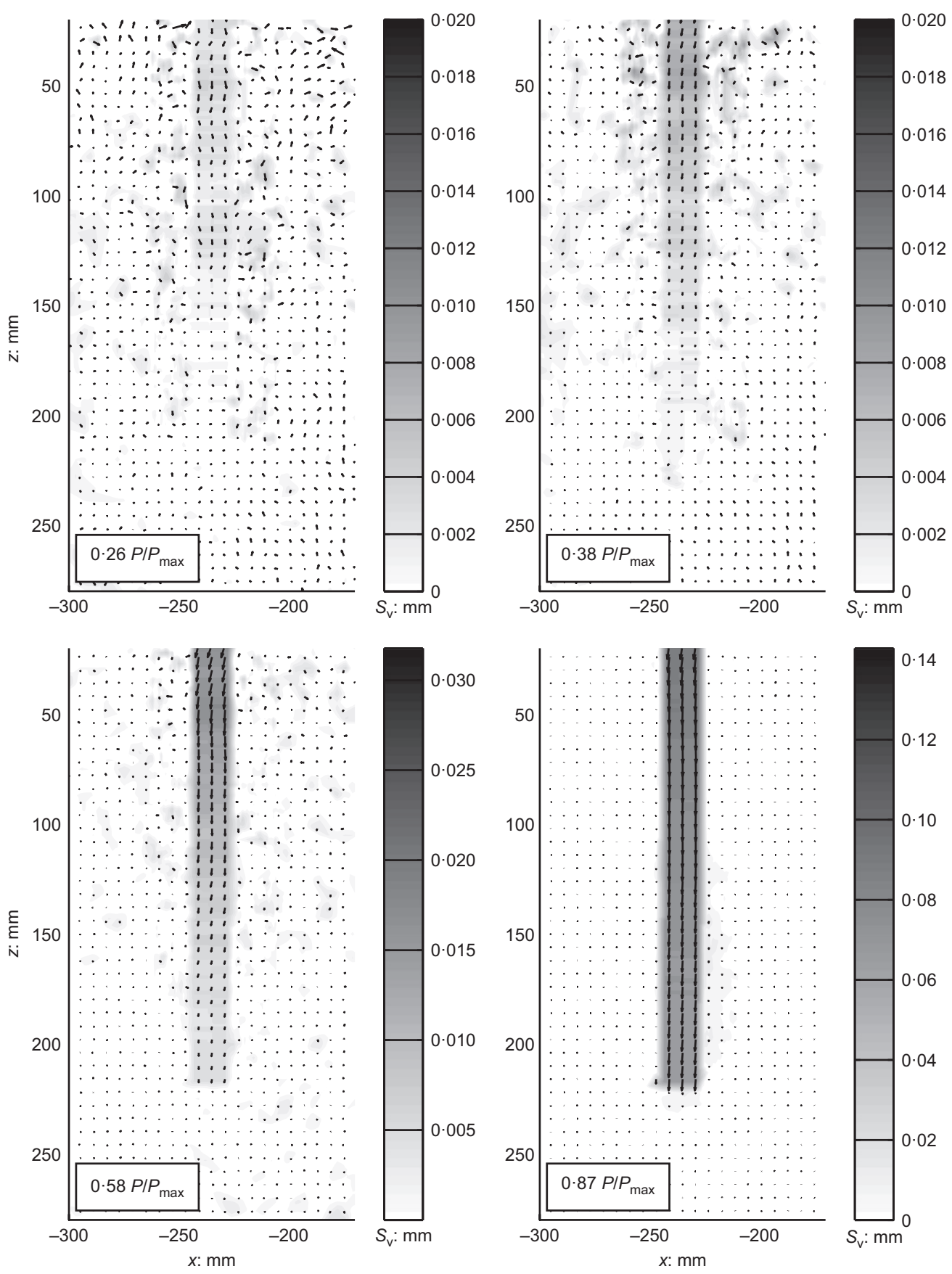

(a)

Fig. 12. Vertical displacement contours during pile load tests: (a) PC4; (b) PC5 (continued on next page) 

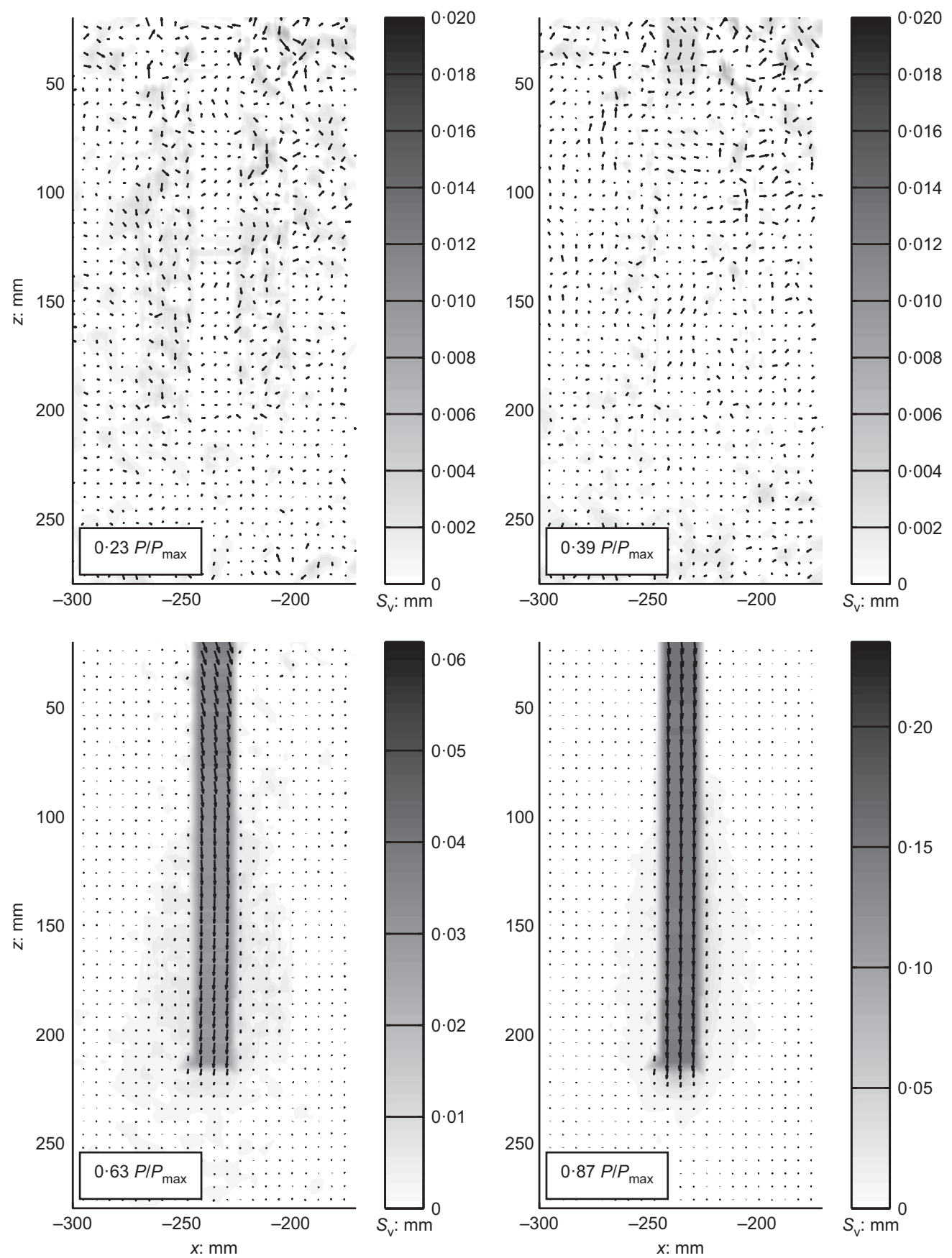

(b)

Fig. 12. Continued

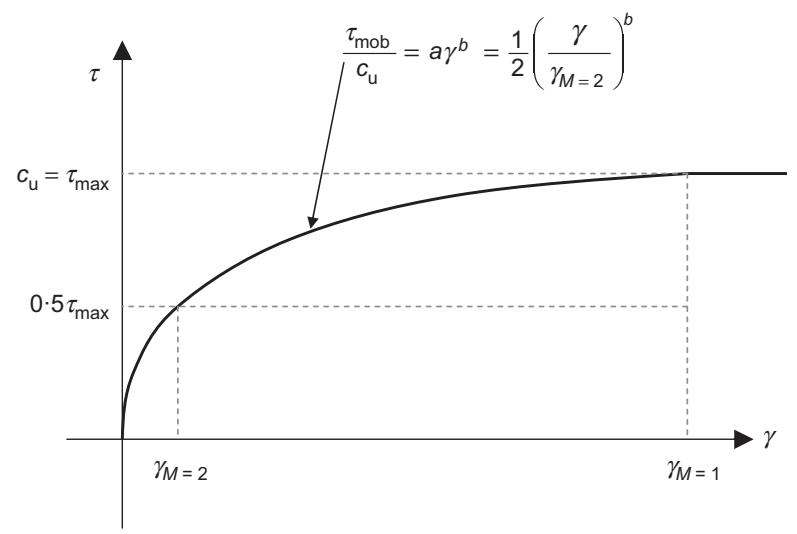

\section{PIV data}

The design of the centrifuge package allowed the measurement of subsurface displacements of both the pile shaft and the adjacent soil and hence it was possible to observe the effect of the model piles on the adjacent soil during loading. Fig. 12 shows the vertical soil displacement contours and the soil displacement vectors for different pile loads in tests PC4 and PC5. The displacement gradients along the piles are visible; these displacements were used for calculation of the change in pile load (see the section headed 'Model preparation').

\section{PILE LOAD TESTS - SOIL MODELLING}

To assess the pile loading results, a simplified 1D non-linear

Fig. 13. Assumed power-law stress-strain model (after Vardanega \& Bolton (2011)) PC5. The analyses were based on the method proposed by 

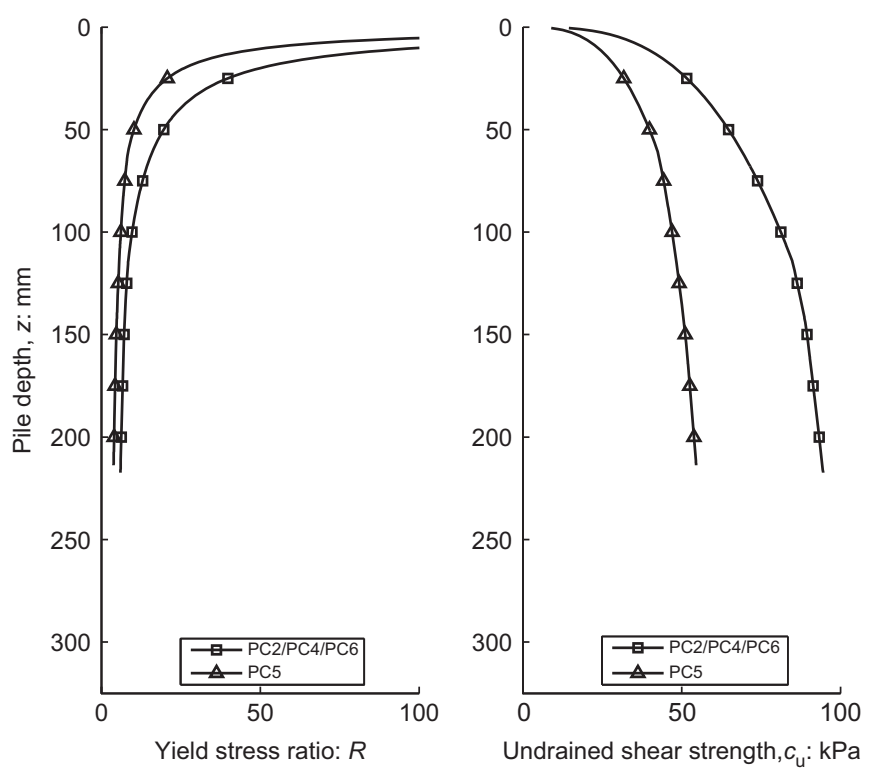

Fig. 14. Power-law model parameters for test series

Vardanega et al. (2012b), which uses the Vardanega \& Bolton (2011) framework for a power-law model of mobilised shear strength for clays as shown in Fig. 13.

In the work presented in this paper, a series of triaxial compression tests was performed on the same batch of Speswhite kaolin used in the test series described in Vardanega et al. (2012a). Based on the stress path analysis described by Williamson (2014), in order to assess the final stress conditions within the clay following consolidation at varying depths, it was possible to predict the clay strength and stiffness using the framework proposed by Vardanega \& Bolton (2011). Fig. 14 shows the calculated yield stress ratio (after (Williamson, 2014)), the predicted undrained shear strength, the predicted strain to mobilise half of the shear strength and the power-law parameter. From this information it was possible to produce load-settlement curves for the piles at various depths.

\section{Predicted pile response during consolidation}

During the consolidation phase, the actual stress-strain behaviour is extremely difficult to estimate. Based on the majority of the soil swelling displacements and load changes during the centrifuge tests occurring towards the end of consolidation, when the stresses were more readily known, the displacement profiles (from PIV) during consolidation that were used in the consolidation analysis are shown in Fig. 15; these are shown relative to the pile toe displacement for clarity. Using these profiles alongside $t-z$ analyses for the piles (as described below) allowed an estimate of the initial shear strain at the soil-pile interface and, in turn, enabled the initial loading to be estimated.

Taking a Winkler spring approach for the $t-z$ model and analysing a single pile element of thickness $\mathrm{d} z$

$$
\begin{aligned}
& \frac{\mathrm{d} w}{\mathrm{~d} z}=\frac{F}{E A} \\
& \frac{\mathrm{d}^{2} w}{\mathrm{~d} z^{2}}=\frac{\mathrm{d} F}{\mathrm{~d} z} \frac{1}{E A}
\end{aligned}
$$

noting that

$$
\frac{\mathrm{d} F}{\mathrm{~d} z}=2 \pi r_{\mathrm{o}} \tau_{\mathrm{o}}
$$
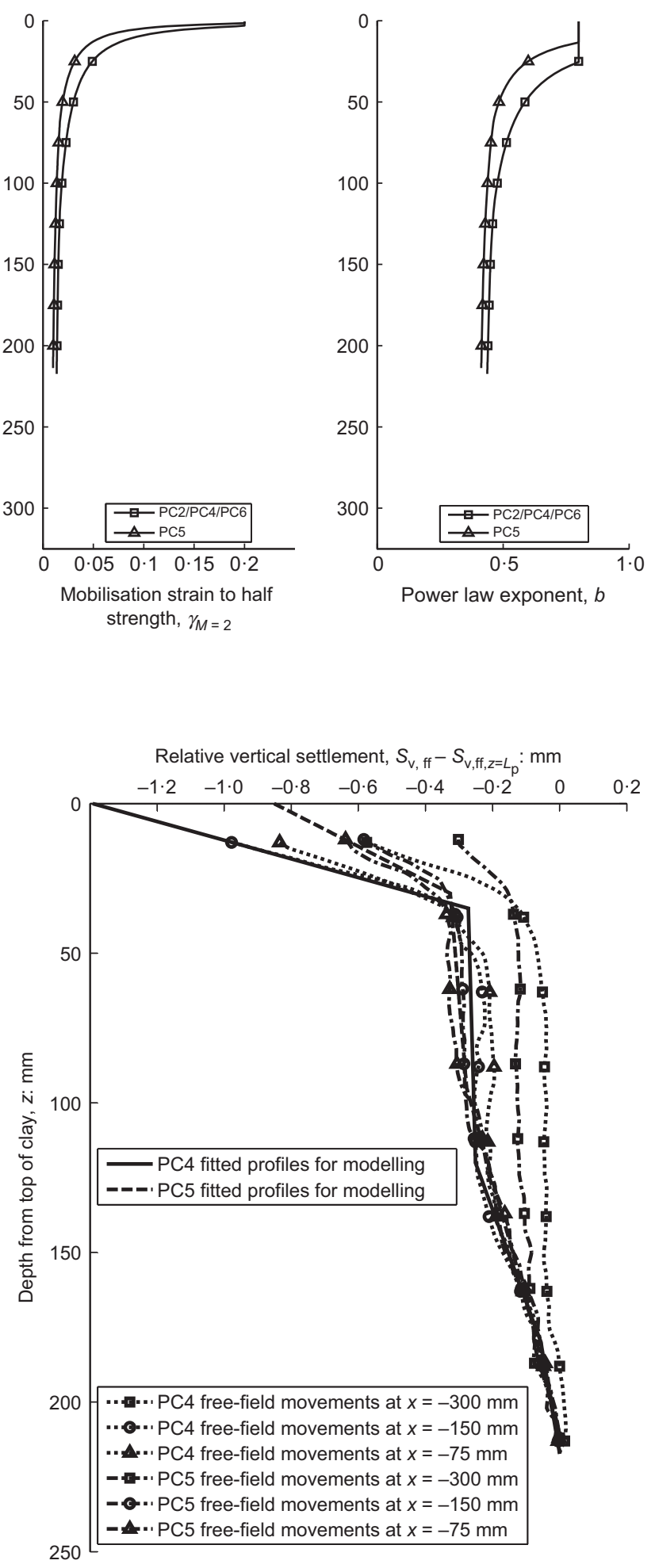

Fig. 15. PIV profiles of soil displacement during consolidation

In these equations, $z$ is the depth below ground level, $w$ is the pile displacement, $F$ is the pile load, $E$ is the Young's modulus of the pile, $A$ is the cross-sectional area of the pile, $r_{\mathrm{o}}$ is the pile radius and $\tau_{\mathrm{o}}$ is shear stress at the pile-soil interface.

Using a standard concentric ring model for piles (Randolph, 1977), which assumes little change in lateral displacement with depth and where $\gamma$ is the shear strain in the soil and $r$ is the distance from the centre of the pile,

$$
\gamma \approx-\frac{\mathrm{d} w}{\mathrm{~d} r}
$$


therefore

$$
\int \mathrm{d} w \approx \int \gamma \mathrm{d} r
$$

For concentric rings of influence, the shear stress $\tau$ at a radius $r$ is

$$
\tau=\frac{\tau_{\mathrm{o}} r_{\mathrm{o}}}{r}
$$

From Vardanega et al. (2012b) and Fig. 13, the shear strain can be rewritten as equation (9) using equation (8), where $\tau_{\mathrm{mob}}$ is the mobilised shear stress in the soil, $c_{\mathrm{u}}$ is the undrained shear strength in the soil, $\gamma_{M=2}$ is the shear strain at half the mobilised strength and $a$ and $b$ are parameters based on soil properties.

$$
\begin{aligned}
& \frac{\tau_{\mathrm{mob}}}{c_{\mathrm{u}}}=a \gamma^{b}=\frac{1}{2}\left(\frac{\gamma}{\gamma_{M=2}}\right)^{b} \\
& \gamma=\gamma_{M=2}\left(\frac{2 \tau}{c_{\mathrm{u}}}\right)^{1 / b}=\gamma_{M=2}\left(\frac{2 \tau_{\mathrm{o}} r_{\mathrm{o}}}{c_{\mathrm{u}} r}\right)^{1 / b} \\
& \int_{0}^{w_{\text {pile }}} \mathrm{d} w=-\int_{r=\infty}^{r=r_{\mathrm{o}}} \gamma_{M=2}\left(\frac{2 \tau_{\mathrm{o}} r_{\mathrm{o}}}{c_{\mathrm{u}}}\right)^{1 / b} r^{-1 / b} \mathrm{~d} r \\
& w_{\text {pile }}=-\gamma_{M=2}\left(\frac{2 \tau_{\mathrm{o}} r_{\mathrm{o}}}{c_{\mathrm{u}}}\right)^{1 / b} \int_{r=\infty}^{r=r_{\mathrm{o}}} r^{-1 / b} \mathrm{~d} r \\
& =-\gamma_{M=2}\left(\frac{2 \tau_{\mathrm{o}} r_{\mathrm{o}}}{c_{\mathrm{u}}}\right)^{1 / b}\left[\frac{b}{b-1} r^{b-1 / b}\right]_{r=\infty}^{r=r_{\mathrm{o}}} \\
& =-\frac{b}{b-1} \gamma_{M=2}\left(\frac{2 \tau_{\mathrm{o}} r_{\mathrm{o}}}{c_{\mathrm{u}}}\right)^{1 / b} r_{\mathrm{o}}^{b-1 / b} \\
& =\frac{b}{1-b} \gamma_{M=2}\left(\frac{2 \tau_{\mathrm{o}}}{c_{\mathrm{u}}}\right)^{1 / b} r_{\mathrm{o}} \\
& \therefore \tau_{\mathrm{o}}=\left(\frac{w_{\text {pile }}}{r_{\mathrm{o}}} \frac{1-b}{b \gamma_{M=2}}\right)^{b} \frac{c_{\mathrm{u}}}{2}
\end{aligned}
$$

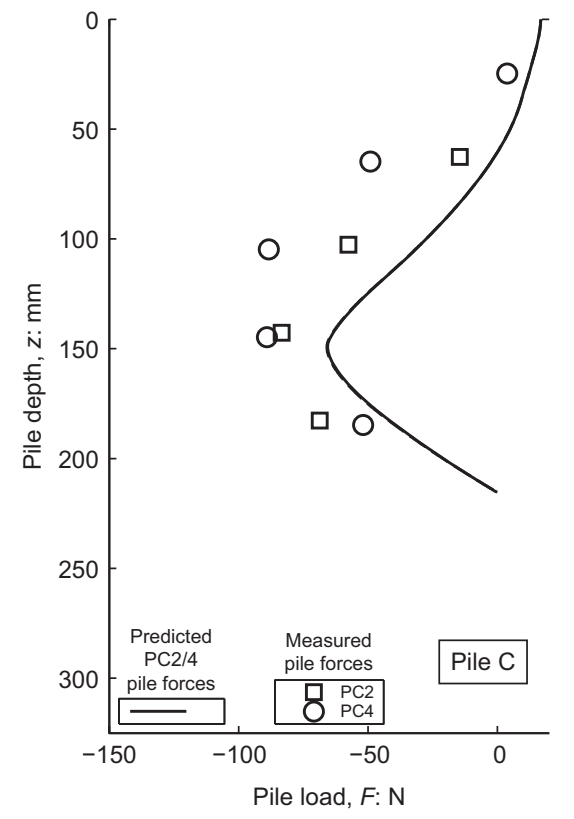

Combining the shear stress with a single pile element to construct a $t-z$ analysis gives

$$
\begin{aligned}
& \frac{\mathrm{d}^{2} w_{\text {pile }}}{\mathrm{d} z^{2}}=\frac{2 \pi r_{\mathrm{o}}}{E A}\left(\frac{w_{\text {pile }}}{r_{\mathrm{o}}} \frac{1-b}{b \gamma_{M=2}}\right)^{b} \frac{c_{\mathrm{u}}}{2} \\
& \frac{\mathrm{d}^{2} w_{\text {pile }}}{\mathrm{d} z^{2}}=\frac{1}{E A}\left[\left(\frac{1-b}{b r_{\mathrm{o}} \gamma_{M=2}}\right)^{b} \pi c_{\mathrm{u}} r_{\mathrm{o}}\right] w_{\text {pile }}^{b}
\end{aligned}
$$

By discretising the pile into elements and applying a finitedifference version of equation (11) when equation (10) is combined with equation (3), and by varying the displacements of the first (base) node and applying a predictorcorrector or Runge-Kutta solver, it is possible to find the head load required to induce the given base displacement. By varying the base displacement, a load-settlement response for the pile can then be calculated.

This method is a sound approach when attempting to quantify the non-linearity of the pile-soil interface using a validated stress-strain model for a number of clays. To allow for some form of non-linearity at the base, the non-linear exponent for the shear stress-shear strain curve was calculated based on the above analysis at the level of the pile base; full mobilisation of the pile base was assumed at $10 \% D_{\mathrm{p}}$.

Figure 16 shows the predicted behaviour of the piles when subjected to consolidation movements; these are compared with the measured loading profiles following temperature compensation. The input parameters to the model are the strength and stiffness parameters in Fig. 14; the consolidation movements in Fig. 15 and the values of $\alpha$ given in Table 3 are based upon the analysis in section 'Illustration of pile capability - pile load tests'. The agreement between the predictions and measurements in Fig. 16 is quite good; at the pile head, the low effective stress had a large impact on the shear stiffness and, based on the model of Vardanega \& Bolton (2011), the values of $\gamma_{M=2}$ and $b$ were limited to $0 \cdot 2$ and $0 \cdot 8$, respectively (Vardanega, 2015, personal communication).

An error in the power-law approach is the infinite stiffness at zero strain, although this has the benefit of integration to infinity such that no 'magic radius' or similar needs to be estimated. Despite this error, at the strains typical of a pile

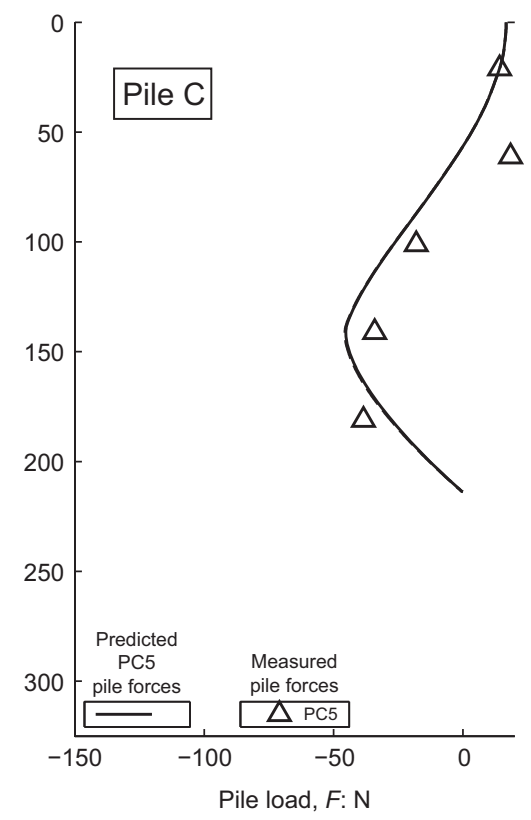

Fig. 16. Non-linear $t-z$ soil loading on piles during consolidation 
under service loads, the model predicted values in reasonable agreement with hyperbolic or 'S-shaped' curves.

An $\alpha-c_{\mathrm{u}}$ approach was applied to limit the skin friction; these values were based on the average shaft capacities and the predicted shear stresses given in Table 3. These were applied for both positive and negative skin friction on the piles.

\section{Pile head loading}

Of most interest is the behaviour of a pile upon reloading having been subjected to consolidation movements and loading. To account for the effect of stress reversal on the piles, the Masing rule (Masing, 1926) was applied for stress reversals (as shown in Fig. 14(d) of the companion paper (Williamson et al., 2017)), providing a stiffer response upon stress reversal for the load-settlement response. The effect of this was to give a stiffer response in the lower section of the pile upon reloading and a softer response in the upper section of the pile based on their initial respective skin frictions. Fig. 17(a) shows the predicted load distributions at salient loads when compared with the measured results.

The predicted response was less stiff than the measured response seen in the piles, as shown in Fig. 18, although the shapes of the curves were well predicted. In addition, the loading behaviour (Fig. 17(a)) and in particular the change in pile load (Fig. 17(b)) with increasing head load was well modelled by the proposed power-law method, providing a good estimate for the expected change in pile load for each of the centrifuge tests.
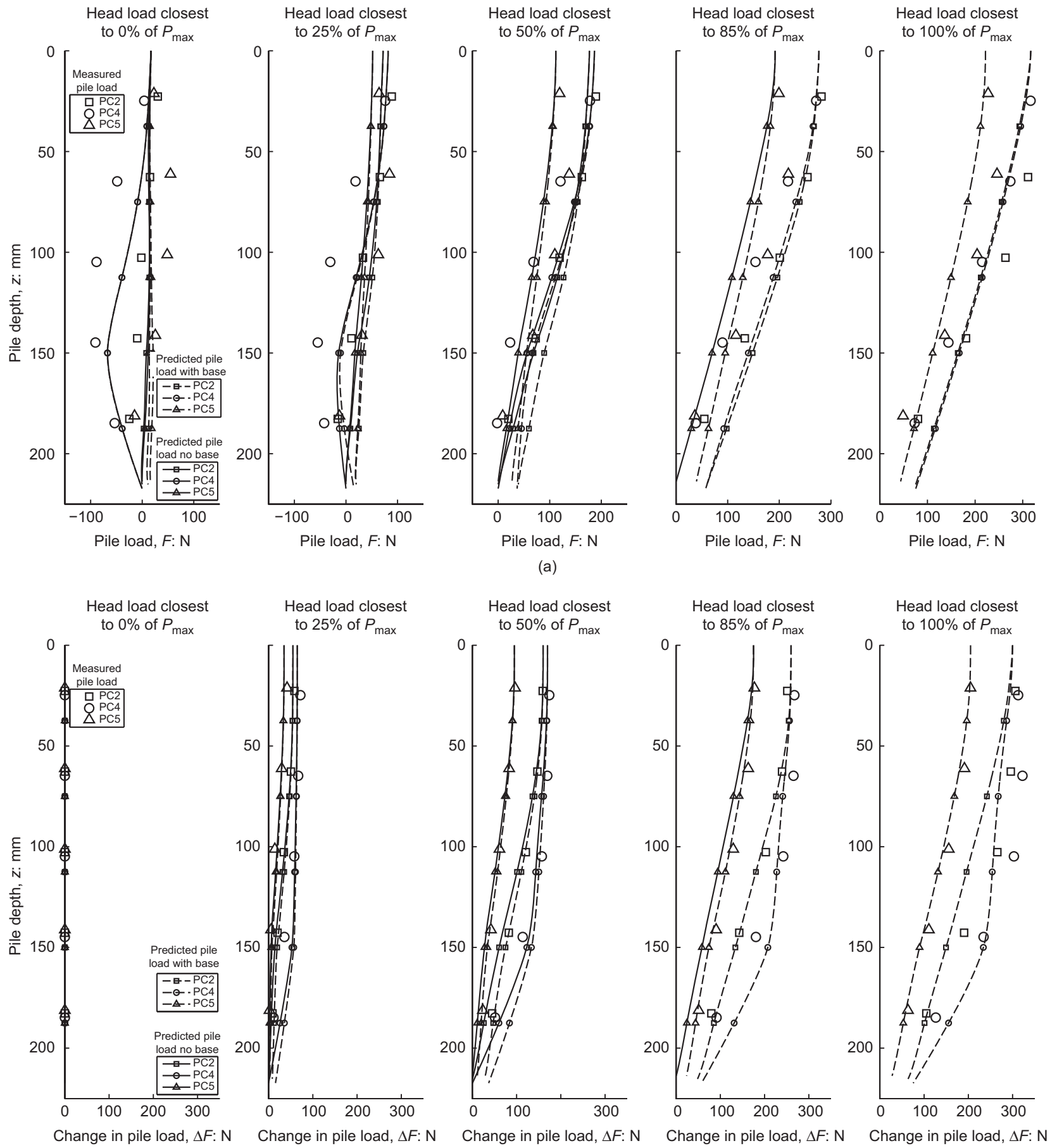

(b)

Fig. 17. Non-linear $t-z$ shaft loading for piles during pile load testing: (a) pile shaft load; (b) change in pile shaft load 

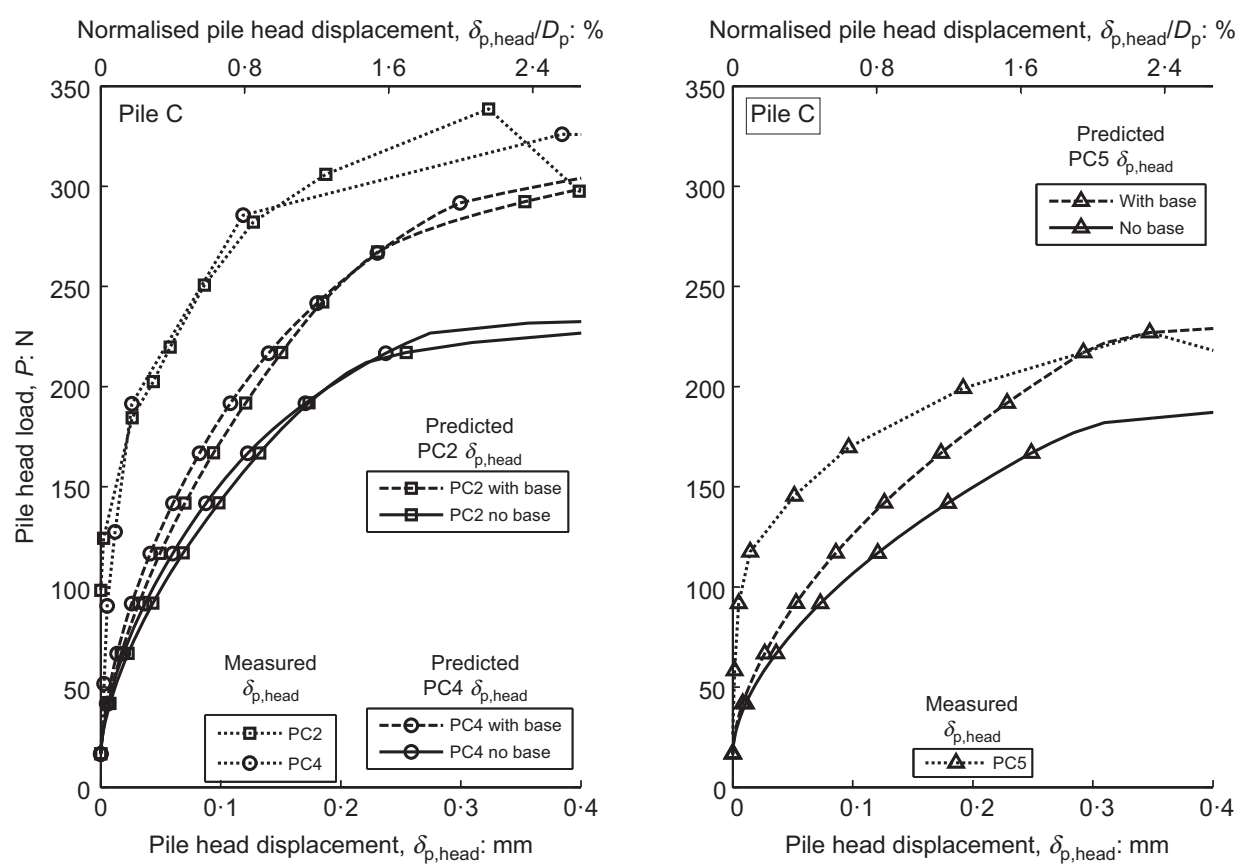

Fig. 18. Non-linear $t-z$ load-settlement response of piles subjected to consolidation movements prior to loading

For both PC2 and PC5, the effects of tunnelling movements prior to pile loading were modelled; for PC4, where pile loading took place prior to tunnelling movements, these effects were not modelled. The effect of this is clear in the initial load distribution of each in Fig. 16. The differences between PC2 and PC4 in the load-settlement curves in Fig. 18 for both the predicted and actual response were very small, indicating no loss of pile capacity due to the tunnelling movements or, indeed, a change in the material properties of the clay.

\section{CONCLUSIONS}

(a) The initial state of a model pile in a centrifuge must be assessed prior to the start of the experimental phase. Failure to do this will result in inaccurate load conditions when attempting to back-analyse the results.

(b) The effect of temperature (of both the pile and the clay body itself) is important when trying to correctly model piles in a centrifuge. It should therefore be carefully considered by both physical and numerical modellers when analysing these and other results.

(c) A reinforced composite pile was successfully used to simulate a non-displacement pile in a centrifuge. Strain gauge (load cell) data and photogrammetric interpretation of the piles agreed extremely well, providing confidence in the results of the load tests and, crucially, the loading changes due to tunnelling reported in the companion paper (Williamson et al., 2017).

(d) The effects of tunnelling-induced ground movements on non-displacement pile capacity in clays in these experiments were found to be minimal. The effect of tunnelling movements did not reduce the amount of shaft capacity and no significant strain softening was observed.

(e) Non-linear $t-z$ modelling based on triaxial data showed the importance of modelling the full stress history of both the soil and the piles and also showed the importance of the allowance for plasticity in such models given the magnitude of consolidation movements seen in the centrifuge.

( $f$ ) The simple $t-z$ model was able to predict the load changes observed on the application of loading in the centrifuge well, although it appears to over-predict settlement of the piles at working loads.

\section{ACKNOWLEDGEMENTS}

The first author acknowledges the financial support provided by Arup Tunnelling and the Engineering and Physical Sciences Research Council for an Industrial Case Studentship. The significant support from technical staff at both the Schofield Centre and Cambridge University Engineering Department is greatly appreciated.

\footnotetext{
NOTATION

A cross-sectional area of pile

a constant coefficient in power-law stress-strain model

$b$ power coefficient in power-law stress-strain model

$c_{T}$ unconstrained calibration factor for voltage changes with change in temperature

$c_{\mathrm{u}} \quad$ undrained shear strength of soil

$D_{\mathrm{p}}$ pile diameter

$\mathrm{d} \delta_{\mathrm{p}, \text { head }} / \mathrm{d} t$ rate of displacement of pile head

$E$ Young's modulus of pile

$F$ pile load

$F_{\text {Soilexp }}$ pile load due to soil movement at the end of consolidation, with temperature compensation

$F_{\text {Soil,exp,raw,No } \Delta T}$ pile load due to soil movement at the end of consolidation, with no temperature compensation

$F_{\text {Soil,st }}$ pile load due to soil movement prior to centrifuge spin-up

$F_{\text {Soil,st,w }}$ pile load due to soil movement prior to centrifuge spin-up with water added

$F_{\text {Soil,su }}$ pile load due to soil movement at the end of centrifuge spin-up

$L_{\mathrm{p}} \quad$ length of pile
} 
$P \quad$ pile head load at top of clay (where not specified this is with temperature and strain rate compensation)

$P_{\mathrm{CRP}}$ peak pile head load at top of clay at a constant rate of penetration (CRP), with temperature compensation

$P_{\max }$ maximum pile head load at top of clay (where not specified this is temperature- and strain-compensated)

$P_{\text {non-CRP }}$ maximum pile head load at top of clay at a maintained loading rate prior to the CRP phase, with temperature compensation

$P_{\text {peak }} \quad$ peak pile head load at top of clay, with temperature compensation

$P_{\text {SPERW }}$ maximum pile head load at top of clay at a CRP, with temperature and strain rate compensation

$R$ yield stress ratio

$r$ distance from centre of pile

$r_{\mathrm{O}} \quad$ pile radius

$S_{\mathrm{v}} \quad$ vertical settlement

$S_{\mathrm{v}, \mathrm{ff}} \quad$ vertical free-field soil settlement

$S_{\mathrm{V}, \mathrm{ff}, z=L_{\mathrm{p}}} \quad$ vertical free-field soil settlement at pile toe

temperature

$V$ measured voltage

$w$ pile vertical displacement

$z$ depth from surface of clay

$\alpha$ shaft adhesion factor

$\gamma \quad$ shear strain

$\gamma_{M=1}$ shear strain to mobilise maximum shear strength of soil

$\gamma_{M=2}$ shear strain to mobilise half the shear strength of soil

$\Delta F$ change in pile load

$\delta_{\mathrm{p}} \quad$ pile displacement

$\delta_{\mathrm{p}, \text { head }}$ pile head displacement

$\delta_{\mathrm{p}} / D_{\mathrm{p}} \quad$ normalised pile displacement

$\delta_{\mathrm{p}, \text { head }} / D_{\mathrm{p}}$ normalised pile head displacement

$\tau_{\max }$ maximum mobilised shear stress

$\tau_{\text {mob }}$ mobilised shear stress

$\tau_{\mathrm{o}} \quad$ shear stress at the pile-soil interface

\section{REFERENCES}

Basile, F. (2012). Pile-group response due to tunnelling. In Proceedings of the 7th international symposium on geotechnical aspects of underground construction in soft ground (ed. G. Viggiani), pp. 781-790. Rotterdam, the Netherlands: Balkema.

Bezuijen, A. \& van der Schrier, J. S. (1994). The influence of a bored tunnel on pile foundations. In Centrifuge 94: proceedings of the international conference on geotechnical centrifuge modelling (eds F. H. Lee, C. F. Leung and T. S. Tan), pp. 681-686. Rotterdam, the Netherlands: Balkema.

Burland, J. B. (1997). Assessment of risk of damage to buildings due to tunnelling and excavation. In Earthquake geotechnical engineering: proceedings of IS-Tokyo '95, the first international conference on earthquake geotechnical engineering (ed. K. Ishihara), vol. 87, pp. 1189-1201. Rotterdam, the Netherlands: Balkema.

Coutts, D. R. \& Wang, J. (2000). Monitoring of reinforced concrete piles under horizontal and vertical loads due to tunnelling. In Tunnels and underground structures (eds J. Zhao, J. N. Shirlaw and R. Krishnan), pp. 541-546. Rotterdam, the Netherlands: Balkema.

Divall, S. (2013). Ground movements associated with twin-tunnel construction in clay. PhD thesis, City University, London, UK.

Farrell, R. P. (2010). Tunnelling in sands and the response of buildings. $\mathrm{PhD}$ thesis, University of Cambridge, Cambridge, UK.

Farrell, R. P., Mair, R. J., Sciotti, A. \& Pigorini, A. (2014). Building response to tunnelling. Soils Found. 54, No. 3, 269-279.

FPS (Federation of Piling Specialists) (2007). ICE specification for piling and embedded retaining walls, 2 nd edn. London, UK: Thomas Telford Publishing.

Franzius, J. N., Potts, D. M. \& Burland, J. B. (2006). The response of surface structures to tunnel construction. Proc. Instn Civ.
Engrs - Geotech. Engng 159, No. 1, 3-17, http://dx.doi.org/ 10.1680/geng.2006.159.1.3

Garnier, J. \& Konig, D. (1998). Scale effects in piles and nails loading tests in sand. In Centrifuge 98: proceedings of the international conference on geotechnical centrifuge modelling (eds T. Kimura, T. Kusakabe and J. Takemura), pp. 205-210. Rotterdam, the Netherlands: Balkema.

Garnier, J., Gaudin, C., Springman, S. M., Culligan, P. J., Goodings, D., Konig, D., Kutter, B., Phillips, R., Randolph, M. F. \& Thorel, L. (2007). Catalogue of scaling laws and similitude questions in geotechnical centrifuge modelling. Int. J. Phys. Model. Geotech. 7, No. 3, 1-24.

Grant, R. J. \& Taylor, R. N. (2000). Tunnelling-induced ground movements in clay. Proc. Instn Civ. Engrs - Geotech. Engng 143, No. 1, 43-55, http://dx.doi.org/10.1680/geng.2000.143.1.43.

Huang, M., Zhang, C. \& Li, Z. (2009). A simplified analysis method for the influence of tunneling on grouped piles. Tunn. Undergr. Space Technol. 24, No. 4, 410-422.

Jacobsz, S. W., Standing, J. R., Mair, R. J., Hagiwara, T. \& Sugiyama, T. (2004). Centrifuge modelling of tunnelling near driven piles. Soils Found. 44, No. 1, 49-56.

Jacobsz, S. W., Bowers, K. H., Moss, N. A. \& Zanardo, G. (2005). The effects of tunnelling on piled foundations on the CTRL. In Proceedings of the 5th international symposium on geotechnical aspects of underground construction in soft ground (eds K. J. Bakker, A. Bezuijen, W. Broere and E. A. Kwast), pp. 115-121. Rotterdam, the Netherlands: Balkema.

Kaalberg, F. J., Teunissen, E. A., van Toi, A. F. \& Bosch, J. W. (2005). Dutch research on the impact of shield tunnelling on pile foundation. In Proceedings of the 5th international symposium on geotechnical aspects of underground construction in soft ground (eds K. J. Bakker, A. Bezuijen, W. Broere and E. A. Kwast), pp. 123-131. Rotterdam, the Netherlands: Balkema.

Kaalberg, F. J., Ruigrok, J. A. T. \& De Nijs, R. (2014). TBM face stability \& excess pore pressures in close proximity of piled bridge foundations controlled with 3D FEM. In Proceedings of the 8th international symposium on geotechnical aspects of underground construction in soft ground (eds C. Yoo, S. W. Park, B. Kim and H. Ban), pp. 555-560. London, UK: Taylor \& Francis.

Kitiyodom, P., Matsumoto, T. \& Kawaguchi, K. (2005). A simplified analysis method for piled raft foundations subjected to ground movements induced by tunnelling. Int. J. Numer. Analyt. Methods Geomech. 29, No. 15, 1485-1507.

Kulhawy, F. H. \& Mayne, P. W. (1990). Manual on estimating soil properties for foundation design, EL-6800. Palo Alto, CA, USA: Electric Power Research Institute.

Lee, C. J. \& Chiang, K. H. (2007). Responses of single piles to tunneling-induced soil movements in sandy ground. Can. Geotech. J. 44, No. 10, 1224-1241.

Lehane, B. M., Gaudin, C. \& Schneider, J. A. (2005). Scale effects on tension capacity for rough piles buried in dense sand. Géotechnique 55, No. 10, 709-719, http://dx.doi.org/10.1680/ geot.2005.55.10.709

Liu, W. (2010). Axisymmetric centrifuge modelling of deep penetration in sand. $\mathrm{PhD}$ thesis, University of Nottingham, Nottingham, UK.

Loganathan, N., Poulos, H. G. \& Stewart, D. P. (2000). Centrifuge model testing of tunnelling-induced ground and pile deformations. Géotechnique 50, No. 3, 283-294, http://dx.doi.org/10. 1680/geot.2000.50.3.283.

Loganathan, N., Poulos, H. G. \& Xu, K. J. (2001). Ground and pile-group responses due to tunnelling. Soils Found. 41, No. 1, $57-67$.

Mair, R. J. (1979). Centrifugal modelling in tunnel construction in soft clay. PhD thesis, University of Cambridge, Cambridge, UK.

Mair, R. J. (2011). Tunnelling and deep excavations: ground movements and their effects. In Geotechnics of hard soils weak rocks: proceedings of the 15th European conference on soil mechanics and geotechnical engineering (eds A. Anagnostopoulos, M. Pachakis and C. Tsatsanifos), pp. 39-70. Amsterdam, the Netherlands: IOS Press.

Mair, R. J. \& Williamson, M. G. (2014). The influence of tunnelling and deep excavation on piled foundations. In Proceedings of the 8th international symposium on geotechnical aspects of underground construction in soft ground (eds C. Yoo, S. W. 
Park, B. Kim and H. Ban), pp. 21-30. London, UK: Taylor \& Francis.

Marshall, A. M. (2012). Tunnel-pile interaction analysis using cavity expansion methods. J. Geotech. Geoenviron. Engng 138, No. 10, 1237-1246.

Marshall, A. M. \& Mair, R. J. (2011). Tunneling beneath driven or jacked end-bearing piles in sand. Can. Geotech. J. 48, No. 12, 1757-1771.

Masing, G. (1926). Eigenspannungen und verfestigung beim messing (Self stretching and hardening for brass). In Proceedings of the 2nd international congress for applied mechanics (ed. E. Meissner), pp. 332-335. Zürich, Switzerland: Orell Füssli Verlag (in German).

McMahon, B. T. (2012). Deformation mechanisms beneath shallow foundations. $\mathrm{PhD}$ thesis, University of Cambridge, Cambridge, UK.

Ng, C. W. W., Lu, H. \& Peng, S. Y. (2013). Three-dimensional centrifuge modelling of the effects of twin tunnelling on an existing pile. Tunn. Undergr. Space Technol. 35, 189-199.

Ong, C. W. (2009). Centrifuge model study of tunnel-soil-interaction in soft clay. PhD thesis, National University of Singapore, Singapore.

Potts, D. M. (1976). Behaviour of lined and unlined tunnels in sand. PhD thesis, University of Cambridge, Cambridge, UK.

Potts, D. M. \& Addenbrooke, T. I. (1997). A structure's influence on tunnelling-induced ground movements. Proc. Instn Civ. Engrs Geotech. Engng 125, No. 2, 109-125, http://dx.doi.org/ 10.1680/igeng.1997.29233.

Randolph, M. F. (1977). A theoretical study of the performance of piles. PhD thesis, University of Cambridge, Cambridge, UK.

Schofield, A. N. (1980). Cambridge geotechnical centrifuge operations. Géotechnique 30, No. 3, 227-268, http://dx.doi.org/ 10.1680/geot.1980.30.3.227.

Selemetas, D. (2005). The response of full-scale piles and piled structures to tunnelling. $\mathrm{PhD}$ thesis, University of Cambridge, Cambridge, UK.

Selemetas, D., Standing, J. R. \& Mair, R. J. (2005). The response of full-scale piles to tunnelling. In Proceedings of the 5th international symposium on geotechnical aspects of underground construction in soft ground (eds K. J. Bakker, A. Bezuijen, W. Broere and E. A. Kwast), pp. 763-769. Rotterdam, the Netherlands: Balkema.

Takahashi, K., Fukazawa, N., Hagiwara, T. \& Hosoda, M. (2004). Observational control of slurry shield tunnels with super close spacing under the nearby bridge abutments. Tunn. Undergr. Space Technol. 19, No. 4, 390-390.
Taylor, R. N. (1998). Modelling of tunnel behaviour. Proc. Instn Civ. Engrs - Geotech. Engng 131, No. 3, 127-132, http://dx.doi.org/ 10.1680/igeng.1998.30467.

Vardanega, P. J. \& Bolton, M. D. (2011). Strength mobilization in clays and silts. Can. Geotech. J. 48, No. 10, 1485-1503.

Vardanega, P. J., Lau, B. H., Lam, S. Y., Haigh, S. K., Madabhushi, S. P. G. \& Bolton, M. D. (2012a). Laboratory measurement of strength mobilisation in kaolin: link to stress history. Géotech. Lett. 2, No. 1, 9-15, http://dx.doi.org/ 10.1680/geolett.12.00003.

Vardanega, P. J., Williamson, M. G. \& Bolton, M. D. (2012b). Bored pile design in stiff clay II: mechanisms and uncertainty. Proc. Instn Civ. Engrs - Geotech Engng 165, No. 4, 233-246, http://dx.doi.org/10.1680/geng.11.00063.

White, D. J. \& Bolton, M. D. (2004). Displacement and strain paths during plane-strain model pile installation in sand. Géotechnique 54, No. 6, 375-397, http://dx.doi.org/10.1680/geot.2004.54. 6.375 .

White, D. J., Take, W. A. \& Bolton, M. D. (2003). Soil deformation measurement using particle image velocimetry (PIV) and photogrammetry. Géotechnique 53, No. 7, 619-631, http:// dx.doi.org/10.1680/geot.2003.53.7.619.

Williamson, M. G. (2014). Tunnelling effects on bored piles in clay. $\mathrm{PhD}$ thesis, University of Cambridge, Cambridge, UK.

Williamson, M. G., Elshafie, M. Z. E. B. \& Mair, R. J. (2013). Centrifuge modelling of bored piles in sands. In Proceedings of the 18th international conference on soil mechanics and geotechnical engineering (eds P. Delage, J. Desrues, R. Frank, A. Peuch and F. Scholosser), pp. 981-984. Paris, France: Presses des Ponts.

Williamson, M. G., Elshafie, M. Z. E. B., Mair, R. J. \& Devriendt, M. D. (2017). Open-face tunnelling effects on non-displacement piles in clay - part 2: tunnelling beneath loaded piles and analytical modelling. Géotechnique, http://dx.doi.org/10.1680/jgeot.sip17.P.120.

Xu, K. J. \& Poulos, H. G. (2001). 3-D elastic analysis of vertical piles subjected to 'passive' loadings. Comput. Geotech. 28, No. 5, 349-375.

Zhang, R. J., Zheng, J. J., Zhang, L. M. \& Pu, H. F. (2011). An analysis method for the influence of tunneling on adjacent loaded pile groups with rigid elevated caps. Int. J. Numer. Analyt. Methods Geomech 35, No. 18, 1949-1971.

Zhang, R. J., Zheng, J. J. \& Yu, S. (2013). Responses of piles subjected to excavation-induced vertical soil movement considering unloading effect and interfacial slip characteristics. Tunn. Undergr. Space Technol. 36, 66-79. 